Published in final edited form as:

J Am Chem Soc. 2021 August 25; 143(33): 13299-13313. doi:10.1021/jacs.1c06339.

\title{
Constraints on the structure of fibrils formed by a racemic mixture of amyloid- $\beta$ peptides from solid state NMR, electron microscopy, and theory
}

\author{
Jevgenij A. Raskatov ${ }^{1}$, Alejandro Foley ${ }^{1}$, John M. Louis ${ }^{2}$, Wai-Ming Yau², Robert Tycko ${ }^{2, *}$ \\ ${ }^{1}$ Department of Chemistry and Biochemistry, University of California, Santa Cruz, CA 95064, USA \\ ${ }^{2}$ Laboratory of Chemical Physics, National Institute of Diabetes and Digestive and Kidney \\ Diseases, National Institutes of Health, Bethesda, MD 20892-0520, USA
}

\begin{abstract}
Previous studies have shown that racemic mixtures of 40- and 42-residue amyloid- $\beta$ peptides (D,L-A $\beta 40$ and D,L-A $\beta 42$ ) form amyloid fibrils with accelerated kinetics and enhanced stability relative to their homochiral counterparts (L-A $\beta 40$ and L-A $\beta 42)$, suggesting a "chiral inactivation" approach to abrogating the neurotoxicity of $A \beta$ oligomers $(A \beta-C I)$. Here we report a structural study of D,L-A $\beta 40$ fibrils, using electron microscopy, solid state nuclear magnetic resonance (NMR), and density functional theory (DFT) calculations. Two- and three-dimensional solid state NMR spectra indicate molecular conformations in D,L-A $\beta 40$ fibrils that resemble those in known L-A $\beta 40$ fibril structures. However, quantitative measurements of ${ }^{13} \mathrm{C}-{ }^{13} \mathrm{C}$ and ${ }^{15} \mathrm{~N}-{ }^{13} \mathrm{C}$ distances in selectively labeled D,L-A $\beta 40$ fibril samples indicate a qualitatively different supramolecular structure. While cross- $\beta$ structures in mature L-A $\beta 40$ fibrils are comprised of in-register, parallel $\beta$-sheets, our data indicate antiparallel $\beta$-sheets in D,L-A $\beta 40$ fibrils, with alternation of D and L molecules along the fibril growth direction, i.e., antiparallel "rippled sheet" structures. The solid state NMR data suggest coexistence of D,L-A $\beta 40$ fibril polymorphs with three different registries of intermolecular hydrogen bonds within the antiparallel rippled sheets. DFT calculations support an energetic preference for antiparallel alignments of the $\beta$-strand segments identified by solid state NMR. These results provide insight into the structural basis for $\mathrm{A} \beta-\mathrm{CI}$ and establish the importance of rippled sheets in self-assembly of full-length, naturally occurring amyloidogenic peptides.
\end{abstract}

\section{Graphical Abstract}

"corresponding author: Dr. Robert Tycko, National Institutes of Health, Building 5, Room 409, Bethesda, MD 20892-0520. phone: 301-402-8272, robertty@mail.nih.gov.

Supporting Information

TEM images of L-A $\beta 40$ and Ac-KLVFFAE-NH 2 fibrils (Figure S1), measurements of nuclear spin relaxation times in REDOR measurements on D,L-A $\beta 40$ fibrils (Figure S2), and comparisons between REDOR data and simulations for various relative populations of intermolecular hydrogen bond registries (Figure S3). Appendix containing atomic coordinates of DFT-optimized structures of LVFFA:lvffa and IIGLM:iiglm. 


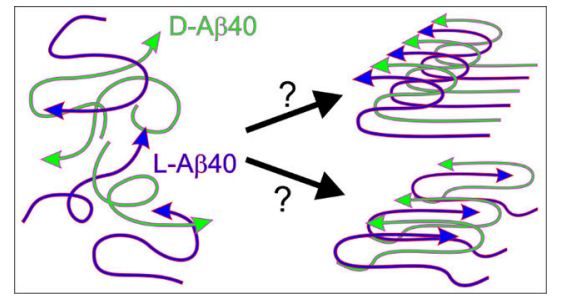

\section{Introduction}

Amyloid- $\beta(A \beta)$ peptides are intrinsically disordered peptides whose aggregated states are believed to be key neurotoxic agents in Alzheimer's disease (AD) ${ }^{1}$. The two predominant $\mathrm{A} \beta$ isoforms in human brain tissue, which are 40 and 42 residues in length (A $\beta 40$ and $\mathrm{A} \beta 42)^{2}$, are both capable of aggregating into a variety of assemblies that are broadly classified as oligomers, protofibrils and fibrils ${ }^{3}$. The molecular structures of A $\beta 40$ and A $\beta 42$ assemblies, formed by conventional L-amino acids, have been studied extensively for more than 20 years ${ }^{4-28}$. Recent experiments have shown that 1:1 mixtures of L-A $\beta$ and mirror-image $\mathrm{D}-\mathrm{A} \beta$ peptides yield fibrillar assemblies with accelerated kinetics and greater stability, suggesting that $\mathrm{D}-\mathrm{A} \beta$ peptides can be used to suppress the formation of non-fibrillar oligomers that may be important neurotoxic species ${ }^{29-31}$. Current interest in self-assembly of racemic peptide mixtures, described in more detail below, motivates the work in this paper.

Although both L-A $\beta 40$ fibrils and L-A $\beta 42$ fibrils are polymorphic, meaning that they can exist in multiple distinct and self-propagating molecular structures $3,5,7,10,17,20,23,28,32-35$, these fibrils possess certain common attributes: (i) As with all amyloid fibrils, they contain "cross- $\beta$ " motifs ${ }^{36-37}$, which are $\beta$-sheets comprised of $\beta$-strand segments that run approximately perpendicular to the fibril growth direction, with their inter-strand hydrogen bonds being approximately parallel to the growth direction; (ii) As originally demonstrated by solid state nuclear magnetic resonance (NMR) and electronic paramagnetic resonance (EPR) ${ }^{4}, 21,38-39$, cross- $\beta$ motifs in mature L-A $\beta 40$ and L-A $\beta 42$ fibrils contain in-register, parallel $\beta$-sheets, meaning that the backbone amide and carbonyl groups of residue $\mathrm{k}$ of one molecule are hydrogen-bonded to backbone carbonyl and amide groups of residues $\mathrm{k}-1$ and $\mathrm{k}+1$, respectively, of a neighboring molecule in the $\beta$-sheet; (iii) Each L-A $\beta 40$ or L-A $\beta 42$ molecule contains multiple $\beta$-strand segments, typically including residues 17-21, 30-32, and 34-36 (sequences LVFFA, AII, and LMV, respectively). Molecular conformations are roughly U-shaped or S-shaped in planes perpendicular to the fibril growth direction ${ }^{6-9}, 17,20,22$, or in some cases are more intricate ${ }^{24,26}$, creating favorable interactions among sidechains of these hydrophobic $\beta$-strand segments that stabilize the overall structures; (iv) N-terminal segments, which contain multiple charged and polar residues, are conformationally disordered ${ }^{4-5,11,20,22}$ or are located on the periphery of the cross- $\beta$ fibril core $9,17,26$; (v) As originally indicated by mass-per-length (MPL) measurements with electron microscopy ${ }^{3,5}, 7,9,39-41$, L-A $\beta 40$ and L-A $\beta 42$ fibrils contain two or three cross- $\beta$ subunits that are related by two-fold or three-fold symmetry about the fibril growth axis, with important hydrophobic interactions between these subunits. Thus, the overall stability of the fibril structures depends on sidechain-sidechain interactions 
both within and between cross- $\beta$ subunits. For L-A $\beta 40$ and L-A $\beta 42$, a single cross- $\beta$ subunit (sometimes called a protofilament ${ }^{42}$ ) does not exist as a stable entity.

Partial exceptions to these structural principles have been observed, illustrating the highly complex nature of $\mathrm{A} \beta$ self-assembly. A recent study of brain-derived L-A $\beta 40$ fibrils, based on a combination of cryogenic electron microscopy (cryoEM), solid state NMR, and MPL measurements, found a polymorph with two-fold symmetry, containing molecules with extended (rather than $\mathrm{U}$-shaped or S-shaped) conformations in its central cross- $\beta$ layers and molecules with partially ordered $\beta$-hairpin-like conformations in its outer cross- $\beta$ layers ${ }^{11}$.

Solid state NMR and MPL data for metastable protofibrils formed by the disease-associated Asp23-to-Asn mutant (D23N-L-A 340 ) indicated U-shaped molecular conformations, but with antiparallel stacking along the fibril growth direction to produce a double-layered cross- $\beta$ motif with purely antiparallel $\beta$-sheets, and with only one cross- $\beta$ subunit ${ }^{8}$. Cross- $\beta$ motifs comprised of antiparallel $\beta$-sheets have also been observed in fibrils formed by short fragments of $\mathrm{L}-\mathrm{A} \beta$, such as residues $34-42^{43}, 16-22^{44}$, and $11-25^{45}$.

In this paper, we report results from a structural study of fibrils formed by a 1:1 mixture of L-A $\beta 40$ and the mirror-image peptide D-A $\beta 40$. Recent work by Raskatov and coworkers has shown that such a racemic mixture yields fibrils with interesting physical properties and potentially important applications in the AD field ${ }^{29,31,46-48}$. Our interest in these "D,L-A $\beta 40$ fibrils" comes from two directions. First, in light of the current understanding of homochiral L-A $\beta$ fibril structures summarized above, it is intriguing to ask whether fibrils that presumably contain a 1:1 mixture of $\mathrm{L}-\mathrm{A} \beta 40$ and $\mathrm{D}-\mathrm{A} \beta 40$ are similar in structure to homochiral fibrils. The answer is not obvious, because a simple replacement of half of the L-A $\beta 40$ molecules by D-A $\beta 40$ molecules would necessarily disrupt any know fibril structure, because the positions of amino acid sidechains relative to the backbone hydrogen-bonding groups of $\beta$-sheets are dramatically different for L-amino acids and D-amino acids ${ }^{48-49}$. The disposition of D- and L-A $\beta 40$ molecules within D,L-A 340 fibrils is also unknown. Although it is tempting to assume that $\mathrm{D}$ and $\mathrm{L}$ monomers alternate along the fibril growth direction within a cross- $\beta$ motif, it is conceivable that a cross- $\beta$ motif constructed from dimers of D-A $\beta 40$ and dimers of $\mathrm{L}-\mathrm{A} \beta 40$, or a more complicated arrangement, exists. It is also conceivable that individual fibrils could contain unequal numbers of L-A $\beta 40$ and D-A 440 molecules and/or lack reflection symmetry (in which case an equal number of fibrils would be expected to have the opposite ratio of L-A $\beta 40$ to D-A $\beta 40$ and/or a mirror-image structure).

Second, Raskatov and coworkers have shown that addition of D-A $\beta$ molecules to $\mathrm{L}-\mathrm{A} \beta$ molecules accelerates fibril formation, thereby suppressing formation of $A \beta$ oligomers that have greater neurotoxicity in cell cultures ${ }^{29-30}$. They introduced the term " $\mathrm{A} \beta$ chiral inactivation" $(\mathrm{A} \beta-\mathrm{CI})$ to describe this approach to the inhibition of $\mathrm{A} \beta$ toxicity by oligomerto-fibril conversion ${ }^{29,50-51}$. A $\beta$-CI is related to the use of D-peptides as fibrillation inhibitors $^{52-55}$ and amyloid-binding compounds ${ }^{52}$, but is distinct in that $\mathrm{D}-\mathrm{A} \beta$ molecules are intended to enhance, rather than suppress, fibril formation by thermodynamic and kinetic effects. Raskatov and coworkers proposed that $\mathrm{A} \beta$-CI works by formation of "rippled sheets" within D,L-A $\beta$ fibrils ${ }^{30-31,46-47}$. Rippled sheets are structural motifs for racemic mixtures of polypeptide chains, introduced in 1953 by Pauling and Corey based on 
theoretical considerations ${ }^{56}$. A rippled sheet is similar to a conventional $\beta$-sheet (also called

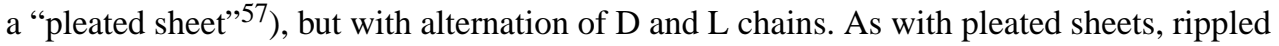
sheets can conceivably exist with either parallel or antiparallel alignments of neighboring, hydrogen-bonded chains ${ }^{56}$.

In amyloid fibrils containing either parallel or antiparallel pleated sheets, amino acid sidechains form rows along the fibril growth direction on both faces of the sheets. In fibrils containing either parallel or antiparallel rippled sheets, amino acid sidechains would form checkerboard patterns on both faces of the sheets ${ }^{48-49}$. Sidechain-sidechain interactions within rippled sheet fibrils may then be quite different from sidechain-sidechain interactions within conventional homochiral fibrils, possibly leading to different molecular structures. Evidence for rippled sheets in amyloid-like fibrils has been reported by Nilsson and coworkers ${ }^{58}$ and Schneider and coworkers ${ }^{49}$, for fibrils with designed amphiphilic sequences, and for Ac-KLVFFAE- $\mathrm{NH}_{2}{ }^{59}$, a fibril-forming peptide based on residues $16-$ 22 of $A \beta^{44}$. However, definitive evidence for rippled sheets in fibrils formed by racemic mixtures of longer, naturally occurring polypeptide sequences, such as $A \beta$ peptides, has not yet been reported. In a study of fibrils formed by a racemic mixture of peptides representing residues $20-41$ of $\beta_{2}$-microglobulin, Goto and coworkers concluded that a rippled sheet structure was not possible ${ }^{60}$. This conclusion was subsequently supported by the spectroscopic studies of Torbeev et al., who also obtained evidence that racemic mixtures of full-length $\beta_{2}$-microglobulin form assemblies with separate domains of $L$ and $D$ protein molecules ${ }^{61}$. Thus, the proposal that $\mathrm{A} \beta-\mathrm{CI}$ works by formation of rippled sheets within $\mathrm{D}, \mathrm{L}-\mathrm{A} \beta$ fibrils requires experimental support from direct structural studies.

Here we present results from solid state NMR measurements on D,L-A $\beta 40$ fibrils, including measurements that identify $\beta$-strand segments and disordered segments and measurements that place constraints on $\beta$-sheet structure. Although these measurements do not fully define the structure of D,L-A $\beta 40$ fibrils, they provide evidence for antiparallel rippled sheets and for polymorphism involving several specific registries of inter-strand hydrogen bonds within the rippled sheets. Electron microscopy measurements complement the solid state NMR data and indicate the presence of three cross- $\beta$ subunits within individual fibrils. Density functional theory (DFT) calculations on the $\beta$-strand segments identified by solid state NMR indicate an energetic preference for antiparallel alignments between neighboring $\mathrm{D}$ and $\mathrm{L}$ molecules. We also discuss aspects of symmetry that distinguish racemic amyloid structures from homochiral structures.

\section{Materials and Methods}

\section{A $\beta 40$ synthesis}

D-A $\beta 40$ without isotopic labels or with ${ }^{15} \mathrm{~N}$ labels at $\mathrm{G} 33$ and $\mathrm{G} 37$ positions within the $A \beta$ framework was synthesized on a CEM Liberty Blue automated microwave-assisted peptide synthesizer using D-Val pre-loaded Tentagel PHB resin (Rapp Polymere). The synthesis was performed at a $0.1 \mathrm{mmol}$ scale relative to resin loading. $30 \%$ piperidine (Spectrum) in dimethylformamide (DMF) was used for deprotection steps, and 1-Hydroxybenzotriazole hydrate (Oakwood Chemical) and N,N'-diisopropylcarbodiimide (DIC, Chem-Impex) were used as amino acid coupling reagents. The D-A $\beta 40$ synthesized peptide was then cleaved 
and deprotected using a cocktail solution of trifluoroacetic acid $(10 \mathrm{~mL}), 1,2$-diethanethiol $(0.5 \mathrm{~mL})$, tri-isopropylsilane $(1 \mathrm{~mL})$ and liquified phenol $(0.5 \mathrm{~mL})$. Peptides were purified by reverse-phase high-performance liquid chromatography (HPLC) to achieve purities higher than $95 \%$ using methods reported previously. ${ }^{62}{ }^{15} \mathrm{~N}-\mathrm{Fmoc}-\mathrm{Gly}-\mathrm{OH}$ was obtained from AnaSpec.

L-A $\beta 40$ with ${ }^{13} \mathrm{C}$-labels at backbone carbonyl sites of I32 and V36 or with ${ }^{13} \mathrm{C}$-labels at backbone carbonyl sites of I31, G33, and M35 and ${ }^{15} \mathrm{~N}$ labels at L17, F19, and A21 was synthesized on a $0.1 \mathrm{mmol}$ scale on a Biotage Initiator+ Alstra synthesizer, using Fmoc chemistry, DIC/OxymaPure activation, and a Fmoc-Val-NovaSyn TGA resin (Millipore-Sigma). Unlabeled residues were double-coupled with a five-fold excess of Fmoc-amino acid for $10 \mathrm{~min}$ at $75^{\circ} \mathrm{C}$, except that Fmoc-Arg(Pbf)-OH was double-coupled for $15 \mathrm{~min}$ at $75^{\circ} \mathrm{C}$ and Fmoc-His(Boc)-OH was double-coupled for $15 \mathrm{~min}$ at $50^{\circ} \mathrm{C}$. For isotopically labeled residues, a three-fold excess of the labeled Fmoc-amino acid was single-coupled for $20 \mathrm{~min}$ at $75^{\circ} \mathrm{C}$, followed by single-coupling with a five-fold excess of unlabeled Fmoc-amino acid for $5 \mathrm{~min}$ at $75^{\circ} \mathrm{C}$. After double-coupling, capping was performed with acetic anhydride/DIPEA to block the ends of unreacted chains and thereby minimize deletion impurities in the final product. Deprotection by $20 \%$ piperidine with $0.1 \mathrm{M}$ 1-Hydroxybenzotriazole hydrate (Sigma-Aldrich) in DMF was performed at $75^{\circ} \mathrm{C}$ for $5 \mathrm{~min}$. Cleavage from the synthesis resin was performed with a standard cocktail for $2.0 \mathrm{~h}$. During the last $15 \mathrm{~min}$ of cleavage, $200 \mathrm{mg}$ of tetrabutylammonium bromide was added to reduce any oxidized methionine at M35 of the A $\beta 40$ sequence. The crude peptide was precipitated in cold methyl tert-butyl ether, washed twice with methyl tert-butyl ether, and purified by preparative HPLC on a Zorbax 300SB-C3 reverse-phase column (Agilent Technologies).

\section{A 340 expression}

For uniformly ${ }^{15} \mathrm{~N},{ }^{13} \mathrm{C}$-labeled L-A $\beta 40$, a DNA insert encoding a 6 His tag followed by the immunoglobulin binding domain $\mathrm{B} 1$ of protein $\mathrm{G}(\mathrm{GB} 1)$, TEV protease cleavage site, and $\mathrm{A} \beta 40$ sequence was cloned into the pJ414 vector (ATUM) and transformed into $E$. coli BL21-DE3 cells (Agilent). The last residue (G/S) in the TEV protease recognition sequence (ENLYFQG/S) was omitted such that upon cleavage the A $\beta 40$ peptide starts with the native $\mathrm{N}$-terminal Asp residue. Cells were grown in minimal medium with ${ }^{15} \mathrm{NH}_{4} \mathrm{Cl}$ and ${ }^{13} \mathrm{C}_{6}$-glucose as the sole nitrogen and carbon sources, respectively. The fusion protein was purified under denaturing conditions by Ni-NTA affinity chromatography. This step was followed by size-exclusion chromatography on a Superdex-75 column (Cytiva) to remove minor high molecular weight contaminants and guanidine hydrochloride and to exchange the buffer to that which is suitable for cleavage by TEV protease. TEV protease was prepared as described by Lucast et al. ${ }^{63}$. After removal of the tag and GB1, as monitored by SDS-PAGE, L-A 340 was collected in the flow-through from the Ni-NTA column and was further purified by reverse-phase HPLC on a POROS 20 R2 column (ThermoFisher Scientific), using a linear gradient from $10 \%$ acetonitrile/water and $0.05 \%$ TFA to 50\% acetonitrile/water and $0.05 \%$ TFA over a period of $8 \mathrm{~min}$ at a flow rate of $4 \mathrm{ml} / \mathrm{min}$. Aliquots of the peak fraction were lyophilized and stored at $-70^{\circ} \mathrm{C}$. Purity was verified both by SDS-PAGE and by electrospray ionization mass spectrometry. Before using this material to 
prepare D,L-A $\beta 40$ fibrils, the lyophilized peptide was dissolved in TFA $(4 \mathrm{mg} / \mathrm{ml}$ peptide concentration), then diluted 10-fold in acetonitrile/water (1:1 by volume), frozen in liquid nitrogen, and lyophilized again.

\section{Fibril preparation}

Fibrils were grown by dissolving purified, lyophilized D-A $\beta 40$ and L-A $\beta 40$ separately in 20 $\mathrm{mM} \mathrm{NaOH}$ at peptide concentrations of $1.2 \mathrm{mM}$. After mixing the two solutions thoroughly, sterile-filtered phophate-buffered saline (PBS) was added to produce a final total peptide concentration of $40 \mu \mathrm{M}$. After thorough mixing, fibrils were allowed to grow quiescently at room temperature. Abundant fibrils were observed in negative-stain TEM images after $24 \mathrm{~h}$, but incubation was allowed to proceed for 5 days. Fibrils were then pelleted at $220,000 \times \mathrm{g}$ (Beckman Coulter SW40Ti rotor) for $4 \mathrm{~h}$, resuspended in $\mathrm{H}_{2} \mathrm{O}$, pelleted again, frozen in liquid nitrogen, and lyophilized. For solid state NMR measurements, the lyophilized fibrils were packed in $1.8 \mathrm{~mm}$-diameter magic-angle spinning (MAS) rotors and rehydrated by addition of $10 \mathrm{mM}$ phosphate buffer, $\mathrm{pH} 7.4$, containing $0.01 \% \mathrm{NaN}_{3}$. Table 1 summarizes the labeling patterns in the four samples that were prepared for solid state NMR measurements.

It is well known that $\mathrm{L}-\mathrm{A} \beta$ fibril structures can be affected by variations in fibril growth conditions $^{5,35}$. To avoid sample-to-sample variations, all D,L-A $\beta 40$ fibril samples were prepared with a single set of conditions, given above. We have not explored the effects of other conditions on D,L-A $\beta 40$ fibril structures.

L-A $\beta 40$ fibrils and Ac-KLVFFAE- $\mathrm{NH}_{2}$ fibrils were prepared as previously described ${ }^{5,44}$. These fibrils were also lyophilized, packed in MAS rotors, and rehydrated with $10 \mathrm{mM}$ phosphate buffer.

\section{Electron microscopy and mass-per-length measurements}

TEM images of negatively stained samples were obtained at $80 \mathrm{keV}$ with a FEI Morgagni microscope and an Advantage HR camera (Advanced Microscopy Techniques). Grids were prepared and stained with uranyl acetate as previously described ${ }^{11}$. Dark-field images of unstained D,L-A $\beta 40$ fibrils for MPL measurements were obtained with the tilted-beam technique described by Chen et al. ${ }^{41}$, using the Morgagni microscope and a XR-550B camera (Advanced Microscopy Techniques). Each count in the MPL histogram in Fig. 6B is the quantity $\left(\mathrm{I}_{\mathrm{F}} / \mathrm{I}_{\mathrm{TMV} \text {,ave }}\right) \times 131 \mathrm{kDa} / \mathrm{nm}$, where $\mathrm{I}_{\mathrm{F}}=\mathrm{F}-0.5\left(\mathrm{~B}_{1}+\mathrm{B}_{2}\right), \mathrm{F}$ is the integrated image intensity within a $100 \mathrm{~nm} \times 40 \mathrm{~nm}$ rectangle centered on a fibril, and $\mathrm{B}_{1}$ and $\mathrm{B}_{2}$ are integrated background intensities in rectangles on either side of the fibril. $\mathrm{I}_{\mathrm{TMV} \text {,ave }}$ is the average of background-subtracted, integrated intensities centered on TMV rods, averaged over 43 measurements. The MPL value of TMV is known to be $131 \mathrm{kDa} / \mathrm{nm}$. Each count in the MPL error histogram in Fig. $6 \mathrm{C}$ is the quantity $\sqrt{\frac{3}{2}}\left[\left(\mathrm{~B}-\mathrm{B}_{\mathrm{ave}}\right) / \mathrm{I}_{\mathrm{TMV}}\right.$,ave $\times 131 \mathrm{kDa} / \mathrm{nm}$, where $\mathrm{B}$ is the integrated intensity in a single background rectangle and $\mathrm{B}_{\mathrm{ave}}$ is the average of B over 206 rectangles. 


\section{Solid state NMR spectroscopy}

Solid state NMR measurements on fibrils with isotopic labels at specific sites were performed at $14.1 \mathrm{~T}\left(150.7 \mathrm{MHz}{ }^{13} \mathrm{C}\right.$ NMR frequency; $60.7 \mathrm{MHz}{ }^{15} \mathrm{~N}$ NMR frequency), using a $1.8 \mathrm{~mm}$ MAS NMR probe obtained from the laboratory of Prof. Ago Samoson (Tallinn University of Technology, Estonia) and either a Varian InfinityPlus spectrometer console or a Tecmag Redstone spectrometer console. Constant-time homonuclear dipolar recoupling with $\pi$ pulses equal to one third of a rotor period (PITHIRDS-CT) ${ }^{64}$ was performed at an MAS frequency of $\nu_{\text {MAS }}=27.00 \mathrm{kHz}$ and a sample temperature of $15^{\circ} \mathrm{C}$ (determined from the temperature-dependent ${ }^{1} \mathrm{H}$ NMR frequency of water in the sample). ${ }^{1} \mathrm{H}$ decoupling field amplitudes were $115 \mathrm{kHz}$ during ${ }^{13} \mathrm{C}-{ }^{13} \mathrm{C}$ dipolar recoupling periods and $85 \mathrm{kHz}$ during signal detection periods, which included pulsed spin-locking for sensitivity enhancement ${ }^{65}$. Rotational echo double resonance (REDOR) measurements used the technique described by Anderson et al. ${ }^{66}$, in which the radio-frequency (rf) pulse sequences for dephased and undephased signals ( $S_{1}$ and $S_{0}$, respectively) differ by only one ${ }^{15} \mathrm{~N} \pi$ pulse in the middle of the ${ }^{15} \mathrm{~N}-{ }^{13} \mathrm{C}$ dipolar recoupling periods. REDOR measurements used $\nu_{\text {MAS }}=9.00 \mathrm{kHz}$, actively rotor-synchronized $10.0 \mu \mathrm{s} \pi$ pulses on the ${ }^{13} \mathrm{C}$ channel and $12.5 \mu$ s $\pi$ pulses on the ${ }^{15} \mathrm{~N}$ channel, $100 \mathrm{kHz}{ }^{1} \mathrm{H}$ decoupling during ${ }^{15} \mathrm{~N}-{ }^{13} \mathrm{C}$ dipolar recoupling periods, and sample temperatures of $4^{\circ} \mathrm{C}$. Pulsed spin-lock detection with 85 $\mathrm{kHz}{ }^{1} \mathrm{H}$ decoupling was used for REDOR data in Fig. 5B. Normal free-induction decay detection with $100 \mathrm{kHz}$ two-pulse phase-modulated (TPPM) decoupling ${ }^{67}$ was used for REDOR data in Fig. 5C. In all REDOR measurements, the number of scans increased linearly with the REDOR recoupling period $\tau_{\text {RED }}$ to maintain an adequate signal-to-noise level at large values of $\tau_{\mathrm{RED}}$. As usual, REDOR data are plotted as $\Delta \mathrm{S} / \mathrm{S}_{0}$, with $\Delta \mathrm{S}=\mathrm{S}_{0}-\mathrm{S}_{1}$.

Measurements of ${ }^{13} \mathrm{C} \mathrm{T}_{2}$ in Fig. S2A used the full REDOR pulse sequence, but without pulses on the ${ }^{15} \mathrm{~N}$ channel. Measurements of effective ${ }^{13} \mathrm{C}$ and ${ }^{15} \mathrm{~N} \mathrm{~T}_{1}$ values in Fig. S2B used pulse sequences in which longitudinal spin magnetization was created by ${ }^{1} \mathrm{H}-{ }^{13} \mathrm{C}$ or ${ }^{1} \mathrm{H}_{-}{ }^{15} \mathrm{~N}$ cross-polarization followed by a $\pi / 2$ "flip-back" pulse. The longitudinal magnetization then evolved under a train of rotor-synchronized ${ }^{13} \mathrm{C}$ or ${ }^{15} \mathrm{~N} \pi$ pulses (with the same XY-16 phase pattern ${ }^{68}$ that was used in REDOR measurements) and was measured by a $\pi / 2$ "read" pulse. Thus, the effective ${ }^{13} \mathrm{C}$ and ${ }^{15} \mathrm{~N} \mathrm{~T}_{1}$ values represent time scales over which longitudinal magnetization decays under the REDOR $\pi$ pulse trains. These values are significant because values less than the relevant ${ }^{15} \mathrm{~N}-{ }^{13} \mathrm{C}$ REDOR dephasing times would prevent determination of ${ }^{15} \mathrm{~N}-{ }^{13} \mathrm{C}$ distances from the REDOR data, due to randomization of nuclear spin states and consequent attenuation of ${ }^{15} \mathrm{~N}-{ }^{13} \mathrm{C}$ dipole-dipole couplings.

Measurements on D,L-A $\beta 40$ fibrils with uniformly ${ }^{15} \mathrm{~N},{ }^{13} \mathrm{C}$-labeled L-A $\beta 40$ were performed at $17.5 \mathrm{~T}$ (187.4 MHz ${ }^{13} \mathrm{C}$ NMR frequency; $75.5 \mathrm{MHz}{ }^{13} \mathrm{C}$ NMR frequency), using a 3.2 mm MAS probe obtained from Dr. Peter Gor'kov (Black Fox, LLC) and a Varian InfinityPlus spectrometer console. The sample temperature was $20^{\circ} \mathrm{C}$, and $\nu_{\text {MAS }}$ was 12.00 kHz. $2 \mathrm{D}{ }^{13} \mathrm{C}-{ }^{13} \mathrm{C}$, NCACX, and NCOCX spectra in Fig. 2 were obtained with standard pulse sequences, with dipole-assisted rotation resonance (DARR) mixing periods of $25 \mathrm{~ms}$ (2D ${ }^{13} \mathrm{C}^{13} \mathrm{C}$ and NCACX) or $50 \mathrm{~ms}$ (2D NCOCX), and $85 \mathrm{kHz}$ TPPM decoupling during $\mathrm{t}_{1}$ and $\mathrm{t}_{2}$ periods. Band-selective ${ }^{15} \mathrm{~N}-{ }^{13} \mathrm{C}$ cross-polarization periods used $8 \mathrm{kHz}$ and $20 \mathrm{kHz}$ rf fields (NCACX) or $32 \mathrm{kHz}$ and $20 \mathrm{kHz}$ rf fields (NCOCX) on ${ }^{13} \mathrm{C}$ and ${ }^{15} \mathrm{~N}$ channels, 
respectively, with $4.0 \mathrm{~ms}$ contact times and a linear ramp of approximately $5 \%$ on the ${ }^{13} \mathrm{C}$ rf amplitude. 3D NCACX, NCOCX, and CANCX measurements in Fig. 3 used the same conditions. Total measurement times were 5-7 days for each 3D spectrum, with 1.8 s recycle delays, time increments of $125 \mu \mathrm{s}$ and $80 \mu \mathrm{s}$, and 32 and 40 complex points in indirect ${ }^{15} \mathrm{~N}$ and ${ }^{13} \mathrm{C}$ dimensions, respectively. The $2 \mathrm{D}^{1} \mathrm{H}_{-}{ }^{13} \mathrm{C}$ INEPT spectrum in Fig. 4 was obtained with the two steps for polarization transfer set to $2.0 \mathrm{~ms}$ and $1.6 \mathrm{~ms}$, and with $10 \mathrm{kHz}{ }^{1} \mathrm{H}$ decoupling using a train of 25 -step composite $\pi$ pulses $^{69}$.

${ }^{13} \mathrm{C}$ and ${ }^{1} \mathrm{H}$ chemical shifts are relative to DSS. ${ }^{15} \mathrm{~N}$ chemical shifts are relative to liquid ammonia. All chemical shift references were determined from the carboxylate ${ }^{13} \mathrm{C}$ chemical shift of D,L-alanine powder under MAS, taken to be 179.65 ppm relative to DSS. 2D and 3D spectra were processed with NMRPipe ${ }^{70}$ and analyzed and plotted with Sparky (available at https://www.cgl.ucsf.edu/home/sparky/). Chemical shifts in Table 1 were determined manually from the 3D spectra.

\section{Simulations of PITHIRDS-CT and REDOR data}

Numerical simulations of PITHIRDS-CT and REDOR data were performed with Fortran programs written specifically for this purpose. For PITHIRDS-CT simulations, the evolution of the nuclear spin density matrix under the time-dependent dipole-dipole coupling Hamiltonian for five ${ }^{13} \mathrm{C}$ spins under MAS with the full PITHIRDS-CT pulse sequence was calculated. Chemical shift anisotropy was not included. In the initial condition, ${ }^{13} \mathrm{C}$ spin polarization was limited to the central spin in a linear chain. Signals from all five spins were detected. This approach approximates the behavior of an infinite chain of spins.

REDOR simulations used formulae for the evolution of a three-spin system (one ${ }^{13} \mathrm{C}$, two ${ }^{15} \mathrm{~N}$, simulations in Figs. 5B, 5D, and S3) or a two-spin system (one ${ }^{13} \mathrm{C}$, one ${ }^{15} \mathrm{~N}$, simulations in Fig. 5C) under an ideal REDOR pulse sequence, assuming $\delta$-function $\pi$ pulses, no chemical shift anisotropy, no spin relaxation, and no ${ }^{15} \mathrm{~N}-{ }^{15} \mathrm{~N}$ couplings. The dashed curve in Fig. 5B used ${ }^{15} \mathrm{~N}-{ }^{13} \mathrm{C}$ distances of $4.2 \AA$ and $5.4 \AA$ and a $162^{\circ}$ angle between the two ${ }^{15} \mathrm{~N}-{ }^{13} \mathrm{C}$ internuclear vectors, representing the two strongest ${ }^{15} \mathrm{~N}-{ }^{13} \mathrm{C}$ dipole-dipole couplings in an antiparallel $\beta$-sheet model for Ac-KLVFFAE- $\mathrm{NH}_{2}$ with $4+\mathrm{k}$ $\leftrightarrow 4$-k registry (i.e., hydrogen bonds between V3 and F5), as determined experimentally by Balbach et al. ${ }^{44}$. The dotted curve in Fig. 5B used ${ }^{15} \mathrm{~N}-{ }^{13} \mathrm{C}$ distances of $4.1 \AA$ and $5.8 \AA$ and a $155^{\circ}$ angle, based on an ideal in-register, parallel $\beta$-sheet model with alternation of $\mathrm{D}$ and L molecules (Fig. 6A). The solid curve in Fig. 5B used ${ }^{15} \mathrm{~N}-{ }^{13} \mathrm{C}$ distances of $6.0 \AA$ and 6.4 $\AA$ and a $107^{\circ}$ angle, based on an ideal antiparallel $\beta$-sheet model with $33+\mathrm{k} \leftrightarrow 33$-k registry (Fig. 6B). The dotted curve in Fig. 5B was scaled down by a factor of 0.7 to account for the expected $30 \%$ contribution of natural-abundance ${ }^{13} \mathrm{C}$ nuclei to the REDOR $\mathrm{S}_{0}$ signals in measurements on $2 \mathrm{C}_{\mathrm{L}}, 2 \mathrm{~N}_{\mathrm{D}}$-D,L-A $\beta 40$ fibrils with a hypothetical in-register, parallel $\beta$-sheet structure. The solid curve in Fig. 5B was scaled down by a factor of 0.35 to account for the contribution of both natural-abundance ${ }^{13} \mathrm{C}$ nuclei and ${ }^{13} \mathrm{C}$ labels at $\mathrm{V} 36$ to the REDOR $\mathrm{S}_{0}$ signals with a hypothetical antiparallel $\beta$-sheet structure (since only the ${ }^{13} \mathrm{C}$ labels at I32 would have significant couplings to ${ }^{15} \mathrm{~N}$ labels). REDOR simulations in Fig. $5 \mathrm{C}$ were scaled down by a factor of 0.38 as described in the Results section. 
REDOR simulations in Figs. 5D and S3 used distances and angles from the ideal antiparallel $\beta$-sheet models in Fig. 6. Simulations for carbonyl ${ }^{13} \mathrm{C}$ labels at I31, I32, G33, M35, or V36 and $33+\mathrm{k} \leftrightarrow 32-\mathrm{k}, 33+\mathrm{k} \leftrightarrow 33-\mathrm{k}$, or $33+\mathrm{k} \leftrightarrow 34-\mathrm{k}$ registry were combined appropriately for comparison with experimental REDOR data. In each simulation, the two ${ }^{15} \mathrm{~N}$ labels that were closest to the ${ }^{13} \mathrm{C}$ label in the $\beta$-sheet model were included. Scaling factors equal to 1 - $f_{\text {nd }}$ were applied to each simulated REDOR curve before comparison with experimental data, where $\mathrm{f}_{\text {nd }}$ is the fraction of the total ${ }^{13} \mathrm{C}$ signal that is expected to have negligible decay from ${ }^{15} \mathrm{~N}-{ }^{13} \mathrm{C}$ dipole-dipole couplings during the recoupling period. Non-decaying signals are attributed to natural-abundance carbonyl ${ }^{13} \mathrm{C}$ spins, estimated to be 0.75 non-glycine carbonyl ${ }^{13} \mathrm{C}$ spins and 0.13 glycine carbonyl ${ }^{13} \mathrm{C}$ spins per D-A $\beta 40 / \mathrm{L}-\mathrm{A} \beta 40$ pair (with minor corrections to account for the presence of ${ }^{13} \mathrm{C}$ labels at some carbonyl sites). $\chi^{2}$ values plotted in Fig. 5D are defined as $\chi^{2}=\sum_{\mathrm{i}=1}^{\mathrm{m}}\left(\mathrm{E}_{\mathrm{i}}-\mathrm{S}_{\mathrm{i}}\right)^{2} / \sigma_{\mathrm{i}}{ }^{2}$, where $\mathrm{m}=17$ is the total number of data points in the REDOR measurements, $E_{i}$ and $S_{i}$ are experimental and simulated $\Delta \mathrm{S} / \mathrm{S}_{0}$ values, and $\sigma_{\mathrm{i}}$ is the uncertainty in $\mathrm{E}_{\mathrm{i}}$. Uncertainties in $\Delta \mathrm{S} / \mathrm{S}_{0}$ were determined from the root-mean-squared noise in the ${ }^{13} \mathrm{C}$ NMR spectra from which $\mathrm{S}_{1}$ and $\mathrm{S}_{0}$ values were measured, following standard error propagation methods.

\section{DFT methods}

Molecular input structures were built from Pauling-Corey coordinates using standard molecular visualization tools and subsequently geometry-optimized at the M062X/6-31G* level of theory using Gaussian0 $9^{71-74}$. Structures were confirmed as minima using frequency calculations. Energies listed are corrected for zero-point energy, basis set superposition error, and solvent contribution (water, polarizable continuum model, single point calculation). The deviation in energy difference between the LVFFA:Ivffa antiparallel and parallel dimers reported here and in our past work is likely due to a combination of factors, including small conformational differences and slightly different levels of theory used $^{48}$.

\section{Results}

\section{Fibril formation by $D, L-A \beta 40$}

Fibrils were prepared by dissolving L-A $\beta 40$ and D-A $\beta 40$ separately at $1.2 \mathrm{mM}$ in 20 $\mathrm{mM} \mathrm{NaOH}$, mixing the two solutions, and diluting them in PBS to a final total peptide concentration of $40 \mu \mathrm{M}$. After quiescent incubation overnight at $24^{\circ} \mathrm{C}$, abundant fibrils were observed in negative-stain transmission electron microscope (TEM) images (Fig. 1A). Fibrils were approximately $7 \pm 1 \mathrm{~nm}$ in width and typically $0.5-2.0 \mu \mathrm{m}$ in length. Unlike many amyloid fibrils formed by L-amino acids ${ }^{3}, 7,10,23,26,28$, the D,L-A $\beta 40$ fibrils do not show a periodic width modulation in the TEM images ${ }^{30}$, suggesting the absence of either right-handed or left-handed twist about the fibril growth direction. A structure that contains equal numbers of equivalent $\mathrm{D}$ and $\mathrm{L}$ molecules is expected to be untwisted. Alternatively, if $\mathrm{D}$ and $\mathrm{L}$ molecules are structurally inequivalent within an individual fibril, equal numbers of fibrils with right-handed and left-handed twists are expected. Indistinguishable fibril morphologies were observed in TEM images after longer incubation periods and in independent sample preparations with different isotopic labeling patterns (Figs. 1B-1D). 


\section{Characterization of peptide conformation and dynamics in D,L-A $\beta 40$ fibrils}

Isotopic labeling patterns of D,L-A $\beta 40$ samples are listed in Table 1. Solid state NMR measurements on $\mathrm{U}_{\mathrm{L}}-\mathrm{D}, \mathrm{L}-\mathrm{A} \beta 40$ fibrils were performed to identify peptide segments that became immobilized or remained dynamic in the fibrils and to characterize the secondary structure of immobilized segments. By symmetry, conclusions drawn from NMR signals of labeled L-A $\beta 40$ molecules in these fibrils should also apply to the unlabeled D-A $\beta 40$ molecules.

Fig. 2 shows two-dimensional (2D) ${ }^{13} \mathrm{C}-{ }^{13} \mathrm{C}, \mathrm{NCACX}$, and NCOCX spectra of the $\mathrm{U}_{\mathrm{L}}$-D,L$\mathrm{A} \beta 40$ fibrils, performed at $17.5 \mathrm{~T}$ and $20^{\circ} \mathrm{C}$ with MAS at $12.00 \mathrm{kHz}$ (see Methods). The 2D spectra are poorly resolved, compared with analogous spectra of certain L-A $\beta 40^{9,24}$ and L-A $\beta 42^{17,} 22$ fibrils. Linewidths in solid state NMR spectra of amyloid fibrils are variable, even for samples that are monomorphic, as the lines can exhibit heterogeneous broadening from intrinsic conformational disorder, disordered contacts between fibrils, or other sources. In the case of D,L-A $\beta 40$ fibrils, the possibility also exists that the molecular structure contains more than one inequivalent peptide conformation or structural environment and/or that the fibril samples contain structurally distinct polymorphs, as discussed below.

Three-dimensional (3D) solid state NMR measurements were performed to obtain site specific assignments of ${ }^{15} \mathrm{~N}$ and ${ }^{13} \mathrm{C}$ chemical shifts. Fig. 3 shows examples of $2 \mathrm{D}$ planes from 3D NCACX, NCOCX, and CONCA spectra of $\mathrm{U}_{\mathrm{L}}-\mathrm{D}, \mathrm{L}-\mathrm{A} \beta 40$ fibrils. Widths of resolved crosspeaks in these spectra are $1.0-1.5 \mathrm{ppm}$ in the ${ }^{13} \mathrm{C}$ dimensions and roughly 2 $\mathrm{ppm}$ in the ${ }^{15} \mathrm{~N}$ dimensions (full widths at half-maxima). Table 2 shows the assignments that could be obtained from manual analysis of the 3D spectra, spanning residues 16-22 and 2937. Chemical shift-based predictions of backbone $\phi$ and $\psi$ torsion angles ${ }^{75}$ indicate $\beta$-strand conformations for the two assigned segments. Thus, these data indicate a strand-loop-strand motif in residues 16-37, similar to what has been observed in previous studies of L-A $\beta 40$ fibrils $^{6-7}$ and protofibrils ${ }^{8,}$. 2 . In D,L-A $\beta 40$ fibrils, the loop in residues $23-28$ is apparently disordered.

Assignments in Table 2 were derived from crosspeaks that are relatively strong and well resolved in the 3D spectra. The spectra also contain weaker and incompletely resolved crosspeaks, which could not be assigned. Unassigned signals may arise from residues outside of the assigned segments or from fibril polymorphs with lower populations.

Fig. 4A shows a $2 \mathrm{D}{ }^{1} \mathrm{H}_{-}{ }^{13} \mathrm{C}$ INEPT spectrum of the $\mathrm{U}_{\mathrm{L}}-\mathrm{D}, \mathrm{L}-\mathrm{A} \beta 40$ fibrils, obtained with experimental conditions that select signals from residues that execute nearly isotropic motions on sub-microsecond time scales (see Methods). From comparisons with standard random-coil ${ }^{1} \mathrm{H}$ and ${ }^{13} \mathrm{C}$ chemical shifts ${ }^{76}$, crosspeaks in this spectrum can be assigned to Ala, Ser, Val, Glu, Phe, Asp, and Arg residues, all of which occur in residues 1-12 (or in residues 1-9 and 38-40) of the A $\beta 40$ sequence. Thus, the $\mathrm{N}$-terminal segment (or the $\mathrm{N}$-terminal and C-terminal segments) are dynamically disordered in D,L-A $\beta 40$ fibrils. Fig. $4 \mathrm{~B}$ summarizes the secondary structure and dynamical information from measurements on $\mathrm{U}_{\mathrm{L}}-\mathrm{D}, \mathrm{L}-\mathrm{A} \beta 40$ fibrils. 


\section{Characterization of $\beta$-sheet organization in D,L-A 340 fibrils}

To obtain constraints on the organization of $\beta$-sheets in D,L-A $\beta 40$ fibrils, measurements of intermolecular ${ }^{13} \mathrm{C}-{ }^{13} \mathrm{C}$ and ${ }^{15} \mathrm{~N}-{ }^{13} \mathrm{C}$ dipole-dipole couplings were performed on samples with ${ }^{13} \mathrm{C}$ labels at specific backbone carbonyl sites and ${ }^{15} \mathrm{~N}$ labels at specific backbone amide sites (see Table 1). Measurements of ${ }^{13} \mathrm{C}-{ }^{13} \mathrm{C}$ couplings in $3 \mathrm{~N}_{\mathrm{L}}, 3 \mathrm{C}_{\mathrm{L}}-\mathrm{D}, \mathrm{L}-\mathrm{A} \beta 40$ fibrils, using the PITHIRDS-CT technique ${ }^{64}$, show a slow decay of ${ }^{13} \mathrm{C}$ solid state NMR signals with increasing dipolar evolution period, consistent with ${ }^{13} \mathrm{C}-{ }^{13} \mathrm{C}$ distances of approximately $7 \AA \mathrm{nm}$ (Fig. 5A). This distance corresponds to the expected intramolecular distances between ${ }^{13} \mathrm{C}$ labels at residues 31,33 , and 35 in $3 \mathrm{~N}_{\mathrm{L}}, 3 \mathrm{C}_{\mathrm{L}}-\mathrm{D}, \mathrm{L}-\mathrm{A} \beta 40$, assuming that the labeled residues are in a $\beta$-strand segment as indicated by the $\phi, \psi$ predictions in Table 2. In contrast, PITHIRDS-CT measurements on L-A $\beta 40$ fibrils with the same labeling pattern show the more rapid signal decay expected for the $4.8 \AA$ intermolecular distances of an in-register, parallel $\beta$-sheet (Fig. 5A; see Fig. S1 for TEM images of the L-A $\beta 40$ fibrils). These PITHIRDS-CT data show that $\beta$-sheets in D,L-A $\beta 40$ fibrils do not contain hydrogenbonded, in-register pairs or larger groups of L-A $\beta 40$ molecules (or D-A $\beta 40$ molecules). Rather, these data are consistent with a rippled sheet structure in which $\mathrm{L}-\mathrm{A} \beta 40$ molecules alternate with D-A $\beta 40$ molecules, with backbone hydrogen bonds only between molecules of opposite chirality.

As shown in Fig. 6A, an in-register, parallel $\beta$-sheet structure with alternating molecular chirality would contain hydrogen bonds between backbone carbonyl groups of residue $\mathrm{k}$ in $\mathrm{L}-\mathrm{A} \beta 40$ and residue $\mathrm{k}+1$ in $\mathrm{D}-\mathrm{A} \beta 40$, leading to intermolecular ${ }^{15} \mathrm{~N}-{ }^{13} \mathrm{C}$ distances of approximately $4.1 \AA$. To test for such a structure, ${ }^{15} \mathrm{~N}-{ }^{13} \mathrm{C}$ dipole-dipole couplings in $2 \mathrm{C}_{\mathrm{L}}, 2 \mathrm{~N}_{\mathrm{D}}$-D,L-A $\beta 40$ fibrils were measured with the REDOR technique ${ }^{66}$. The build-up of normalized REDOR difference signals $\Delta \mathrm{S} / \mathrm{S}_{0}$ (where $\Delta \mathrm{S}=\mathrm{S}_{1}-\mathrm{S}_{0}$, with $\mathrm{S}_{1}$ and $\mathrm{S}_{0}$ being the ${ }^{13} \mathrm{C}$ signal amplitudes with and without net evolution under ${ }^{15} \mathrm{~N}-{ }^{13} \mathrm{C}$ couplings) is too slow to be consistent with 4.1 A distances between carbonyl ${ }^{13} \mathrm{C}$ labels at I32 and V36 and ${ }^{15} \mathrm{~N}$ labels at G33 and G37, respectively (Fig. 5B). These data rule out an in-register, parallel rippled sheet structure.

Since REDOR build-up can be suppressed by molecular motions that tend to average out ${ }^{15} \mathrm{~N}-{ }^{13} \mathrm{C}$ couplings and by ${ }^{13} \mathrm{C}$ or ${ }^{15} \mathrm{~N}$ nuclear spin dephasing during the dipolar evolution period, measurements were performed on both hydrated and lyophilized $2 \mathrm{C}_{\mathrm{L}}, 2 \mathrm{~N}_{\mathrm{D}^{-}}$ $\mathrm{D}, \mathrm{L}-\mathrm{A} \beta 40$ fibrils, leading to indistinguishable data. As additional checks, measurements of dephasing under the REDOR pulse sequence yielded dephasing times $\left(\mathrm{T}_{2}\right.$ for ${ }^{13} \mathrm{C}$ and effective $\mathrm{T}_{1}$ for both ${ }^{13} \mathrm{C}$ and ${ }^{15} \mathrm{~N}$, see Fig. S2) that were not sufficiently short to prevent observation of a $4.1 \AA^{15} \mathrm{~N}-{ }^{13} \mathrm{C}$ distance. Moreover, REDOR measurements on Ac-KLVFFAE- $\mathrm{NH}_{2}$ fibrils with ${ }^{15} \mathrm{~N}$ labels at $\mathrm{V} 3$ and ${ }^{13} \mathrm{C}$ labels at carbonyl sites of $\mathrm{F} 5$ produced a rapid build-up of $\Delta \mathrm{S} / \mathrm{S}_{0}$ under the same experimental conditions (Fig. $5 \mathrm{~B}$; see Fig. $\mathrm{S} 1$ for TEM images of Ac-KLVFFAE- $\mathrm{NH}_{2}$ fibrils). Data for Ac-KLVFFAE-NH $\mathrm{N}_{2}$ fibrils are in quantitative agreement with simulations (dashed curve in Fig. 5B) that are based on intermolecular distances in the know antiparallel $\beta$-sheet structure of Ac-KLVFFAE- $\mathrm{NH}_{2}$ fibrils, which includes V3-F5 hydrogen bonds ${ }^{44}$.

An antiparallel rippled sheet structure could potentially explain the data for D,L-A $\beta 40$ fibrils in Figs. 5A and 5B. For example, as shown in Fig. 6B, an antiparallel $\beta$-sheet formed by 
residues 29-37, with hydrogen bonds between residue $33+\mathrm{k}$ of one molecule and residue $33-\mathrm{k}$ of a neighboring molecule (i.e., 33+k $\leftrightarrow 33-\mathrm{k}$ registry of intermolecular hydrogen bonds within the antiparallel $\beta$-sheet), would lead to nearest-neighbor intermolecular distances between $\mathrm{I} 32{ }^{13} \mathrm{C}$ labels and $\mathrm{G} 33{ }^{15} \mathrm{~N}$ labels of approximately $6.0 \AA$ and $6.4 \AA$ in $2 \mathrm{C}_{\mathrm{L}}, 2 \mathrm{~N}_{\mathrm{D}}$-D,L-A $\beta 40$ fibrils, and to nearest-neighbor ${ }^{15} \mathrm{~N}-{ }^{13} \mathrm{C}$ distances greater than 10 $\AA$ for the V36 ${ }^{13} \mathrm{C}$ label. Simulations in Fig. 5B (solid curve) show that such a structure fits the experimental REDOR data reasonably well. Antiparallel $\beta$-sheets with $33+\mathrm{k} \leftrightarrow$ $33-\mathrm{k}$ registry do exist in D23N-L-A $\beta 40$ protofibrils ${ }^{8}$. However, other rippled sheet structures could also explain the data in Figs. 5A and 5B.

As an additional constraint, REDOR measurements were performed on $3 \mathrm{~N}_{\mathrm{L}}, 3 \mathrm{C}_{\mathrm{L}}, 2 \mathrm{~N}_{\mathrm{D}}-\mathrm{D}, \mathrm{L}$ $\mathrm{A} \beta 40$ fibrils, in which the carbonyl ${ }^{13} \mathrm{C}$ NMR line from the label at G33 in L-A $\beta 40$ was resolved from the ${ }^{13} \mathrm{C}$ NMR line from labels at I31 and M35. Data in Fig. 5C show a relatively rapid build-up of $\Delta \mathrm{S} / \mathrm{S}_{0}$ for the G33 line, consistent with the expected intermolecular distance of approximately $4.1 \AA$ between ${ }^{13} \mathrm{C}$ labels at G33 in L-A 340 and ${ }^{15} \mathrm{~N}$ labels at G33 in D-A $\beta 40$ with $33+\mathrm{k} \leftrightarrow 33-\mathrm{k}$ registry. However, the maximum value of $\Delta \mathrm{S} / \mathrm{S}_{0}$ is only about 0.35 , indicating that not all G33 carbonyl ${ }^{13} \mathrm{C}$ labels have this ${ }^{15} \mathrm{~N}-{ }^{13} \mathrm{C}$ distance. REDOR simulations in Fig. $5 \mathrm{C}$ are scaled by a factor of 0.38 to optimize agreement with the experimental data. Thus, it appears that our D,L-A $\beta 40$ fibrils may contain antiparallel rippled sheets with $33+\mathrm{k} \leftrightarrow 33-\mathrm{k}$ registry, but that fewer than half of the $\mathrm{A} \beta 40$ molecules participate in this hydrogen bond registry.

We tested other registries, using models for antiparallel rippled sheets to determine the nearest-neighbor ${ }^{15} \mathrm{~N}-{ }^{13} \mathrm{C}$ distances with the isotopic labeling patterns of the $2 \mathrm{C}_{\mathrm{L}}, 2 \mathrm{~N}_{\mathrm{D}}-\mathrm{D}, \mathrm{L}-$ $\mathrm{A} \beta 40$ and $3 \mathrm{~N}_{\mathrm{L}}, 3 \mathrm{C}_{\mathrm{L}}, 2 \mathrm{~N}_{\mathrm{D}}-\mathrm{D}, \mathrm{L}-\mathrm{A} \beta 40$ samples. Models for $33+\mathrm{k} \leftrightarrow 32-\mathrm{k}$ and $33+\mathrm{k} \leftrightarrow 34-\mathrm{k}$ registry are shown in Figs. $6 \mathrm{C}$ and 6D. No single registry resulted in acceptable agreement between all experimental REDOR data and simulations. We also considered (admittedly implausible) models with mixed registry within a single rippled sheet, for example a model with a four-molecule repeat pattern, with hydrogen bonds between G33 of molecule $i$ and G33 of molecule $i+1$, L34 of molecule $i+1$ and G33 of molecule $i+2$, L34 of molecule $i+2$ and I32 of molecule $i+3$, and G33 of molecule $i+3$ and L34 of molecule $i+4$. We were unable to construct a single model, even with mixed registry, that resulted in acceptable agreement between all experimental REDOR data and simulations.

The failure of a single rippled sheet model to explain the experimental REDOR data leads us to conclude that our D,L-A $\beta 40$ fibril samples are polymorphic, containing fibrils (or domains within individual fibrils) with different antiparallel rippled sheet structures. The experimental REDOR data are then population-weighted averages of data for the different structures. To estimate the relative populations, we performed REDOR simulations for each of the five ${ }^{13} \mathrm{C}$-labeled carbonyl sites in the $2 \mathrm{C}_{\mathrm{L}}, 2 \mathrm{~N}_{\mathrm{D}}$-D, L- $\mathrm{A} \beta 40$ and $3 \mathrm{~N}_{\mathrm{L}}, 3 \mathrm{C}_{\mathrm{L}}, 2 \mathrm{~N}_{\mathrm{D}}-\mathrm{D}, \mathrm{L}-$ A 340 samples, with $33+k \leftrightarrow 32-k, 33+k \leftrightarrow 33-k$, and $33+k \leftrightarrow 34-k$ registries. Simulations included ${ }^{15} \mathrm{~N}-{ }^{13} \mathrm{C}$ dipole-dipole couplings to the two nearest-neighbor ${ }^{15} \mathrm{~N}$ labels in each registry, as well as corrections for signal contributions from natural-abundance carbonyl ${ }^{13} \mathrm{C}$ spins as described in the Methods section. Simulations for I32 and V36 in $2 \mathrm{C}_{\mathrm{L}}, 2 \mathrm{~N}_{\mathrm{D}^{-}}$ $\mathrm{D}, \mathrm{L}-\mathrm{A} \beta 40$ fibrils and for $\mathrm{I} 31$ and $\mathrm{M} 35$ in $3 \mathrm{~N}_{\mathrm{L}}, 3 \mathrm{C}_{\mathrm{L}}, 2 \mathrm{~N}_{\mathrm{D}}-\mathrm{D}, \mathrm{L}-\mathrm{A} \beta 40$ fibrils were added 
together, since the corresponding solid state NMR signals were not resolved in the REDOR measurements.

Fig. 5D shows the dependence of the total $\chi^{2}$ deviation between experimental and simulated REDOR data on the fractions of the three registries in the simulations (see Methods for definition of $\chi^{2}$ ). The best agreement between experiments and simulations (i.e., minimum $\chi^{2}$ ) occurs with roughly $25 \% 33+\mathrm{k} \leftrightarrow 32-\mathrm{k}$ registry, $15 \% 33+\mathrm{k} \leftrightarrow 33-\mathrm{k}$ registry, and $60 \%$ $33+\mathrm{k} \leftrightarrow 34-\mathrm{k}$ registry. Simulations for these polymorph populations are compared directly with experimental data in Fig. S3A. Comparisons for several other choices of the polymorph populations, with larger $\chi^{2}$ values are shown in Figs. S3B-S3D.

The minimum $\chi^{2}$ value was not reduced when all simulated REDOR $\Delta \mathrm{S} / \mathrm{S}_{0}$ values were multiplied by any factor less than one. This indicates that polymorphs with large ${ }^{15} \mathrm{~N}-{ }^{13} \mathrm{C}$ distances simultaneously for all carbonyl ${ }^{13} \mathrm{C}$ labels in $2 \mathrm{C}_{\mathrm{L}}, 2 \mathrm{~N}_{\mathrm{D}}-\mathrm{D}, \mathrm{L}-\mathrm{A} \beta 40$ and $3 \mathrm{~N}_{\mathrm{L}}, 3 \mathrm{C}_{\mathrm{L}}, 2 \mathrm{~N}_{\mathrm{D}}-\mathrm{D}, \mathrm{L}-\mathrm{A} \beta 40$ fibrils have negligible populations.

Our solid state NMR measurements do not place direct constraints on the $\beta$-sheet organization for residues 17-21, which form $\beta$-strands according to the chemical shift data (Table 2). The antiparallel $\beta$-sheet alignment of residues 30-36 strongly suggests antiparallel $\beta$-sheet formation by residues $17-21$, which is also supported by the DFT results described below.

\section{Mass-per-length of D,L-A $\beta 40$ fibrils}

The mass-per-length (MPL) value of a single cross- $\beta$ motif in an amyloid fibril is MW/d $\mathrm{d}_{\beta}$, where MW is the molecular weight of the peptide and $\mathrm{d}_{\beta} \approx 0.48 \mathrm{~nm}$ is the spacing between peptide molecules in a $\beta$-sheet, assuming that each molecule contributes one $\beta$-strand to the $\beta$-sheet. For $A \beta 40, M W / \mathrm{d}_{\beta} \approx 9.0 \mathrm{kDa} / \mathrm{nm}$. The MPL value of $\mathrm{D}, \mathrm{L}-\mathrm{A} \beta 40$ fibrils can be determined by a quantitative analysis of intensities in dark-field TEM images of unstained samples $3,39-41$, as shown in Fig. 7A. The histogram of MPL counts in Fig. 7B indicates a value of $26.6 \pm 0.5 \mathrm{kDa} / \mathrm{nm}$, indicating that each D,L-A $\beta 40$ fibril contains three cross- $\beta$ subunits. The width of this histogram does not arise from variations in MPL values of individual fibrils. Rather, this width is due to noise in the dark-field images, as shown by the nearly identical width of the histogram of background fluctuations in Fig. 7C.

\section{Results from DFT calculations}

Solid state NMR measurements presented above show that residues 16-21 (KLVFFA)and $31-35$ (IIGLM) of L-A $\beta 40$ and D-A $\beta 40$ participate in cross- $\beta$ motifs in D,L-A $\beta 40$ fibrils. The data are consistent with an alternating, heterochiral (i.e., rippled) antiparallel $\beta$-sheet structure, although with several coexisting registries.

In previous work, we used DFT calculations to study mirror-image peptide recognition leading to rippled sheet formation in model systems ${ }^{30,46-47}$. Employing similar DFT methods, we performed geometry optimizations for heterochiral dimers in either parallel or antiparallel orientation, for both LVFFA:lvffa and IIGLM:iiglm (with lower-case letters indicating D-amino acids), which are $\beta$-strand segments according to their assigned ${ }^{13} \mathrm{C}$ and ${ }^{15} \mathrm{~N}$ chemical shifts (Table 2). Viable geometry-optimized low energy conformers are 
shown in Fig. 8. Atomic coordinates are given in the Appendix in Supporting Information. A general preference for the antiparallel over the parallel rippled cross- $\beta$ interface is noted, in agreement with the experimental data. Specifically, we find the antiparallel orientation is preferred by $6.1 \mathrm{kcal} / \mathrm{mol}$ and $3.9 \mathrm{kcal} / \mathrm{mol}$ for LVFFA:Ivffa and IIGLM:iiglm, respectively.

\section{Discussion}

\section{Summary of structural constraints}

2D and 3D solid state NMR spectra in Figs. 2 and 3 provide evidence for a D,L-A 340 fibril structure in which residues 16-37 form the cross- $\beta$ core, with partial disorder or dynamics in residues $23-28$. The $2 \mathrm{D}^{1} \mathrm{H}^{-13} \mathrm{C}$ INEPT spectrum in Fig. 4 shows that the $\mathrm{N}$-terminal segments of $\mathrm{A} \beta 40$, and possibly the $\mathrm{C}$-termini, are dynamically disordered, executing large amplitude motions on sub-microsecond time scales. The relatively poor resolution of the 2D spectra in Fig. 2 is a likely result of internal disorder in residues 23-28 and the $\mathrm{N}$ - and C-terminal segments, as well as the polymorphism and symmetry considerations discussed below. Despite this disorder, the chemical shift assignments in Table 2 could be made from the 3D spectra, leading to the identification of residues $17-21$ and 30-36 as $\beta$-strands.

Data in Figs. 5A and 5B rule out in-register parallel cross- $\beta$ structures, either with two or more consecutive L-A $\beta 40$ molecules (or D-A $\beta 40$ molecules) in the hydrogen-bonding direction or with alternation of D-A $\beta 40$ and L-A $\beta 40$. In-register parallel structures would produce a more rapid PITHIRDS-CT signal decay for D,L-A $\beta 40$ fibrils in Fig. 5A or a more rapid build-up of REDOR signal in Fig. 5B. As an alternative, we consider antiparallel cross- $\beta$ structures, similar to the structure for D $23 \mathrm{~N}-\mathrm{L}-\mathrm{A} \beta 40$ protofibrils determined by Qiang et al. ${ }^{8}$, but with the alternation of D-A $\beta 40$ and L-A $\beta 40$ (i.e., antiparallel rippled sheets). In the D23N-L-A 440 protofibril structure (Protein Data Bank code 2LNQ), D23NL-A $\beta 40$ molecules adopt $U$-shaped conformations, with $\beta$-strand conformations in residues 16-23 and 30-36 and a loop in residues 24-39. Intermolecular hydrogen-bonding along the fibril growth direction produces a double-layered antiparallel $\beta$-sheet structure, with $19+\mathrm{k}$ $\leftrightarrow 19-\mathrm{k}$ registry in the "bottom" layer and 33+k $\leftrightarrow 33-\mathrm{k}$ registry in the "top" layer. REDOR data for G33 in Fig. 5C test for such a structure. The relatively rapid build-up of $\Delta \mathrm{S} / \mathrm{S}_{0}$ for G33 suggests $33+\mathrm{k} \leftrightarrow 33-\mathrm{k}$ registry, but involving fewer than half of the D-A 340 and L-A 340 molecules. An acceptable fit to REDOR data for G33 and I31/M35 in Fig. 5C and for I32/V36 in Fig. 5B can be obtained by assuming that the D,L-A 340 samples contain fibrils (or domains within fibrils) with $33+\mathrm{k} \leftrightarrow 32-\mathrm{k}, 33+\mathrm{k} \leftrightarrow 33-\mathrm{k}$, and $33+\mathrm{k} \leftrightarrow 34-\mathrm{k}$ registries, with populations near 25\%,15\%, and 60\%, respectively (Figs. 5D and S3).

MPL measurements in Fig. 7 provide strong support for an overall fibril structure comprised of three cross- $\beta$ subunits. Each cross- $\beta$ subunit contains antiparallel rippled sheets. Our data do not tell us whether all subunits within a single fibril have the same hydrogen bond registry.

\section{Symmetry in D,L-A $\beta 40$ fibrils}

One might expect the $\mathrm{D}, \mathrm{L}-\mathrm{A} \beta 40$ fibril structure to have maximal symmetry, meaning that both D-A $\beta 40$ molecules and L-A $\beta 40$ molecules have a single conformation and structural 
environment, with $\mathrm{D}$ and $\mathrm{L}$ molecules interchanged by a reflection, followed by some combination of translations and rotations of the overall structure. Maximal symmetry is observed in many experimentally determined structures for amyloid fibrils $9,17,22,24,26$, although exceptions exist ${ }^{11,77}$.

If the $\mathrm{D}, \mathrm{L}-\mathrm{A} \beta 40$ fibril structure contained only a single cross- $\beta$ layer, there would be many $\beta$-sheet structures with maximal symmetry in which $\mathrm{D}$ and $\mathrm{L}$ molecules alternate along the hydrogen-bonding direction (i.e., the fibril growth direction). Examples include the in-register, parallel $\beta$-sheet model and the three antiparallel $\beta$-sheet models in Fig. 6A-6D. However, real L-A $\beta 40$ and L-A $\beta 42$ fibril structures contain more than one $\beta$-strand segment, forming more than one cross- $\beta$ layer ${ }^{6-9}, 17,20,22,24,26$. In this case, as depicted in Fig. $6 \mathrm{E}$, an in-register, parallel rippled sheet structure for $\mathrm{D}, \mathrm{L}-\mathrm{A} \beta 40$ fibrils loses symmetry because sidechains of a given residue in the $\mathrm{D}-\mathrm{A} \beta 40$ and $\mathrm{L}-\mathrm{A} \beta 40$ molecules point in different directions, either towards or away from the fibril core. Similarly, as depicted in Fig. 6F, antiparallel rippled sheets with $\mathrm{q}+\mathrm{k} \leftrightarrow \mathrm{q}-\mathrm{k}$ hydrogen bonding registry, meaning that residue $\mathrm{q}$ of a D-A $\beta 40$ molecule is hydrogen bonded to residue $\mathrm{q}$ of an L-A $\beta 40$ molecule for some integer $q$, lose symmetry when the overall fibril structure contains more than one cross- $\beta$ layer. In such rippled sheets, inter-strand hydrogen bonds exist only between even-numbered residues or between odd-numbered residues. Again, loss of symmetry results from the different directions for sidechains of a given residue in the D-A 340 and L-A 440 molecules.

On the other hand, antiparallel rippled sheets with $\mathrm{q}+\mathrm{k} \leftrightarrow \mathrm{q}-\mathrm{k} \pm 1$ registry, meaning that hydrogen bonds exist only between odd-numbered residues of D-A $\beta 40$ and even-numbered residues of L-A $\beta 40$ (and vice versa) can retain maximal symmetry in a structure with more than one cross- $\beta$ layer, because sidechains of a given residue in the D-A 340 and L-A $\beta 40$ molecules point in the same direction. In principle, out-of-register parallel rippled sheets, with inter-strand hydrogen bonds from residue $\mathrm{k}$ to residues $\mathrm{k}-2 / \mathrm{k}$ or $\mathrm{k} / \mathrm{k}+2$ for odd or even $\mathrm{k}$ could also retain maximal symmetry. To our knowledge, out-of-register parallel $\beta$-sheets have not been observed in structural studies of any amyloid fibrils.

Our data indicate partial population of antiparallel rippled sheets with $33+\mathrm{k} \leftrightarrow 33-\mathrm{k}$ registry in D,L-A $\beta 40$ fibril samples. Since, D and L molecules are inequivalent within such structures, two types of fibrils (or domains within fibrils) must exist, one with I32 sidechains of L-A $\beta 40$ molecules pointing away from the fibril core, the other with I32 sidechains of D-A 440 molecules pointing away from the fibril core (for example). The existence of two inequivalent $33+\mathrm{k} \leftrightarrow 33-\mathrm{k}$ structures, with equal populations, may contribute to the relatively poor resolution of $2 \mathrm{D}$ and $3 \mathrm{D}$ solid state NMR spectra of $\mathrm{U}_{\mathrm{L}}-\mathrm{D}, \mathrm{L}-\mathrm{A} \beta 40$ fibrils, along with the other sources of polymorphism and disorder discussed above.

\section{DFT molecular modeling}

Using DFT computational methods, we generated the molecular structures of rippled interfaces for the hydrophobic segments LVFFA:lvffa and IIGLM:iiglm (Fig. 7), both of which show an energetic preference for the antiparallel rippled arrangement. While the preference for antiparallel alignment is consistent with the solid state NMR data, it should be kept in mind that more than one structure exists in D,L-A 440 fibril samples, and also that different $A \beta$ folds may fit to accommodate the structural elements proposed 
here. Furthermore, our past work showed that some of the chiral interactions favoring rippled sheet formation are established in a trimer, but not a dimer in fibril growth dimension ${ }^{47}$. This was attributed to steric pressure between sidechains in the homochiral (i.e., pleated), but not the heterochiral (i.e., rippled) trimer, which led to distortion of hydrogen-bonding networks in the former but not the latter. Future theory work considering larger segments in fibril growth direction may provide a more complete understanding of $A \beta-C I$. Interactions between $A \beta$ molecules orthogonal to fibril growth direction (of which our MPL measurements suggest there are three per layer) may further fine-tune the mirror-image interactions underlying A $\beta$-CI. Theoretical studies that take those complex interactions into account would be of great interest, and it would be particularly interesting to have molecular modeling work performed, in which fibril formation is considered explicitly, so as to gain insights into kinetics of $\mathrm{A} \beta$-CI.

\section{Concluding remarks}

Evidence for rippled sheets has been obtained in previous studies of amyloid-like fibrils formed by racemic mixtures of the designed peptides MAX $1^{49,78}$ and $\mathrm{KFE} 8^{58}$, as well as in fibrils formed by racemic Ac-KLVFFAE- $\mathrm{NH}_{2}{ }^{59}$. Support for coassembly of D and $\mathrm{L}$ molecules in these studies comes from electron microscopy ${ }^{49,58-59}$, fluorescence resonance energy transfer ${ }^{58}$, calorimetry ${ }^{58}$, equilibrium solubilities ${ }^{59}$, circular dichroism ${ }^{78}$, and rheology 49,78 . Support for alternation of $\mathrm{D}$ and $\mathrm{L}$ molecules within $\beta$-sheets, i.e., for rippled sheets, comes primarily from isotope-edited infrared spectroscopy $49,58-59$, and solid state $\mathrm{NMR}^{49,59}$. Very recently, Grelich-Mucha et al. ${ }^{79}$ have used infrared and fluorescence spectroscopies and molecular dynamics simulations to support an antiparallel rippled sheet structure in fibrils formed by a racemic mixture of peptides with the sequence YTIAALLSPYS (residues 105-115 of transthyretin). Homochiral YTIAALLSPYS fibrils were previously shown to contain in-register, parallel $\beta$-sheets ${ }^{80}$.

Our results for D,L-A $\beta 40$ fibrils extend these previous studies in several important ways. First, $A \beta 40$ is a naturally occurring peptide with a higher molecular weight, more diverse amino acid composition, and greater conformational complexity than peptides in the previous studies. Our results in support of rippled sheets in D,L-A $\beta 40$ fibrils suggest that rippled sheet formation is a generic property of racemic mixtures of amyloidogenic peptides, rather than a phenomenon that might be limited to peptides with designed features or short sequences. Our results also suggest that antiparallel rippled sheets may generally be thermodynamically preferred over parallel rippled sheets, even for sequences that prefer inregister, parallel cross- $\beta$ structures in homochiral samples. Moreover, our solid state NMR data show that, like many homochiral amyloid fibrils, fibrils formed by racemic mixtures of amyloidogenic peptides can exhibit molecular-level structural polymorphism, including polymorphism based on variations in hydrogen bond registry within antiparallel rippled sheets. In addition to contributing to our understanding of $\mathrm{A} \beta-\mathrm{CI}$ and to racemic peptide assemblies in general, these structural findings may contribute to the further development of amyloid inhibitors based on D-amino acids ${ }^{52-55}$.

The fact that $\mathrm{D}, \mathrm{L}-\mathrm{A} \beta 40$ fibrils and $\mathrm{L}-\mathrm{A} \beta 40$ fibrils contain qualitatively different cross- $\beta$ structures is likely to be a consequence of differences in sidechain packing and sidechain- 
sidechain interactions. In homochiral fibrils, the in-register, parallel cross- $\beta$ structure is favored by intermolecular interactions that depend on linear rows of like residues, including sidechain hydrogen bonds among Gln residues ${ }^{81}, \pi$-stacking of aromatic sidechains ${ }^{82}$, and hydrophobic interactions. These interactions may not be available in rippled sheets, shifting the energetic balance toward antiparallel structures. Future studies by theory and experimental methods may further elucidate the interactions that favor specific rippled sheet structures in fibrils formed by racemic mixtures of amyloidogenic peptides.

\section{Supplementary Material}

Refer to Web version on PubMed Central for supplementary material.

\section{Acknowledgments}

This work was supported by the Intramural Research Program of the National Institute of Diabetes and Digestive and Kidney Diseases, National Institutes of Health. JAR thanks the University of California at Santa Cruz for support from flexible start-up funds and the National Institutes of Health for support under award R21AG058074. ARF was supported by NIH fellowship 2R25GM058903-20-IMSD.

\section{References}

1. Selkoe DJ; Hardy J, The amyloid hypothesis of Alzheimer's disease at 25 years. EMBO Mol. Med2016, 8, 595-608. [PubMed: 27025652]

2. Gravina SA; Ho LB; Eckman CB; Long KE; Otvos L; Younkin LH; Suzuki N; Younkin SG, Amyloid- $\beta$ protein $(A \beta)$ in Alzheimers-disease brain: Biochemical and immunocytochemical analysis with antibodies specific for forms ending at $A \beta 40$ or $A \beta 42(43)$. J. Biol. Chem1995, 270, 7013-7016. [PubMed: 7706234]

3. Goldsbury C; Frey P; Olivieri V; Aebi U; Muller SA, Multiple assembly pathways underlie amyloid$\beta$ fibril polymorphisms. J. Mol. Biol2005, 352, 282-298. [PubMed: 16095615]

4. Antzutkin ON; Balbach JJ; Leapman RD; Rizzo NW; Reed J; Tycko R, Multiple quantum solidstate NMR indicates a parallel, not antiparallel, organization of $\beta$-sheets in Alzheimer's $\beta$-amyloid fibrils. Proc. Natl. Acad. Sci. USA2000, 97, 13045-13050. [PubMed: 11069287]

5. Petkova AT; Leapman RD; Guo ZH; Yau WM; Mattson MP; Tycko R, Self-propagating, molecularlevel polymorphism in Alzheimer's $\beta$-amyloid fibrils. Science2005, 307, 262-265. [PubMed: 15653506]

6. Petkova AT; Yau WM; Tycko R, Experimental constraints on quaternary structure in Alzheimer's $\beta$-amyloid fibrils. Biochemistry2006, 45, 498-512. [PubMed: 16401079]

7. Paravastu AK; Leapman RD; Yau WM; Tycko R, Molecular structural basis for polymorphism in Alzheimer's $\beta$-amyloid fibrils. Proc. Natl. Acad. Sci. USA2008, 105, 18349-18354. [PubMed: 19015532]

8. Qiang W; Yau WM; Luo YQ; Mattson MP; Tycko R, Antiparallel $\beta$-sheet architecture in Iowamutant $\beta$-amyloid fibrils. Proc. Natl. Acad. Sci. USA2012, 109, 4443-4448. [PubMed: 22403062]

9. Lu JX; Qiang W; Yau WM; Schwieters CD; Meredith SC; Tycko R, Molecular structure of $\beta$-amyloid fibrils in Alzheimer's disease brain tissue. Cell2013, 154, 1257-1268. [PubMed: 24034249]

10. Qiang W; Yau WM; Lu JX; Collinge J; Tycko R, Structural variation in amyloid- $\beta$ fibrils from Alzheimer's disease clinical subtypes. Nature2017, 541, 217-221. [PubMed: 28052060]

11. Ghosh U; Thurber KR; Yau WM; Tycko R, Molecular structure of a prevalent amyloid- $\beta$ fibril polymorph from Alzheimer's disease brain tissue. Proc. Natl. Acad. Sci. USA2021, 118, e2023089118. [PubMed: 33431654]

12. Potapov A; Yau WM; Ghirlando R; Thurber KR; Tycko R, Successive stages of amyloid- $\beta$ self-assembly characterized by solid-state nuclear magnetic resonance with dynamic nuclear polarization. J. Am. Chem. Soc2015, 137, 8294-8307. [PubMed: 26068174] 
13. Kheterpal I; Williams A; Murphy C; Bledsoe B; Wetzel R, Structural features of the A $\beta$ amyloid fibril elucidated by limited proteolysis. Biochemistry2001, 40, 11757-11767. [PubMed: 11570876]

14. Williams AD; Sega M; Chen ML; Kheterpal I; Geva M; Berthelier V; Kaleta DT; Cook KD; Wetzel R, Structural properties of A $\beta$ protofibrils stabilized by a small molecule. Proc. Natl. Acad. Sci. USA2005, 102, 7115-7120. [PubMed: 15883377]

15. Kheterpal I; Chen M; Cook KD; Wetzel R, Structural differences in A $\beta$ amyloid protofibrils and fibrils mapped by hydrogen exchange: Mass spectrometry with on-line proteolytic fragmentation. J. Mol. Biol2006, 361, 785-795. [PubMed: 16875699]

16. Luhrs T; Ritter C; Adrian M; Riek-Loher D; Bohrmann B; Doeli H; Schubert D; Riek R, 3D structure of Alzheimer's amyloid- $\beta(1-42)$ fibrils. Proc. Natl. Acad. Sci. USA2005, 102, 1734217347. [PubMed: 16293696]

17. Walti MA; Ravotti F; Arai H; Glabe CG; Wall JS; Bockmann A; Guntert P; Meier BH; Riek R, Atomic-resolution structure of a disease-relevant $A \beta(1-42)$ amyloid fibril. Proc. Natl. Acad. Sci. USA2016, 113, E4976-E4984. [PubMed: 27469165]

18. Chimon S; Shaibat MA; Jones CR; Calero DC; Aizezi B; Ishii Y, Evidence of fibril-like $\beta$-sheet structures in a neurotoxic amyloid intermediate of Alzheimer's $\beta$-amyloid. Nat. Struct. Molec. Biol2007, 14, 1157-1164. [PubMed: 18059284]

19. Parthasarathy S; Inoue M; Xiao YL; Matsumura Y; Nabeshima Y; Hoshi M; Ishii Y, Structural insight into an Alzheimer's brain-derived spherical assembly of amyloid $\beta$ by solid-state NMR. J. Am. Chem. Soc2015, 137, 6480-6483. [PubMed: 25938164]

20. Xiao YL; Ma BY; McElheny D; Parthasarathy S; Long F; Hoshi M; Nussinov R; Ishii Y, A $\beta(1-42)$ fibril structure illuminates self-recognition and replication of amyloid in Alzheimer's disease. Nat. Struct. Molec. Biol2015, 22, 499-505. [PubMed: 25938662]

21. Torok M; Milton S; Kayed R; Wu P; McIntire T; Glabe CG; Langen R, Structural and dynamic features of Alzheimer's A $\beta$ peptide in amyloid fibrils studied by site-directed spin labeling. J. Biol. Chem2002, 277, 40810-40815. [PubMed: 12181315]

22. Colvin MT; Silvers R; Ni QZ; Can TV; Sergeyev I; Rosay M; Donovan KJ; Michael B; Wall J; Linse S; Griffin RG, Atomic resolution structure of monomorphic A $\beta(42)$ amyloid fibrils. J. Am. Chem. Soc2016, 138, 9663-9674. [PubMed: 27355699]

23. Kollmer M; Close W; Funk L; Rasmussen J; Bsoul A; Schierhorn A; Schmidt M; Sigurdson CJ; Jucker M; Fandrich M, Cryo-EM structure and polymorphism of A $\beta$ amyloid fibrils purified from Alzheimer's brain tissue. Nat. Commun2019, 10, 4760. [PubMed: 31664019]

24. Schutz AK; Vagt T; Huber M; Ovchinnikova OY; Cadalbert R; Wall J; Guntert P; Bockmann A; Glockshuber R; Meier BH, Atomic-resolution three-dimensional structure of amyloid $\beta$ fibrils bearing the Osaka mutation. Angew. Chem.-Int. Edit. 2014, 53, 1-6.

25. Scheidt HA; Morgado I; Huster D, Solid-state NMR reveals a close structural relationship between amyloid- $\beta$ protofibrils and oligomers. J. Biol. Chem2012, 287, 22822-22826. [PubMed: 22589542]

26. Gremer L; Scholzel D; Schenk C; Reinartz E; Labahn J; Ravelli RBG; Tusche M; Lopez-Iglesias C; Hoyer W; Heise H; Willbold D; Schroder GF, Fibril structure of amyloid- $\beta(1-42)$ by cryoelectron microscopy. Science2017, 358, 116-119. [PubMed: 28882996]

27. Schmidt M; Rohou A; Lasker K; Yadav JK; Schiene-Fischer C; Fandrich M; Grigorieff N, Peptide dimer structure in an $A \beta(1-42)$ fibril visualized with cryo-EM. Proc. Natl. Acad. Sci. USA2015, 112, 11858-11863. [PubMed: 26351699]

28. Meinhardt J; Sachse C; Hortschansky P; Grigorieff N; Fandrich M, A $\beta(1-40)$ fibril polymorphism implies diverse interaction patterns in amyloid fibrils. J. Mol. Biol2009, 386, 869-877. [PubMed: 19038266]

29. Dutta S; Foley AR; Warner CJA; Zhang X; Rolandi M; Abrams B; Raskatov JA, Suppression of oligomer formation and formation of non-toxic fibrils upon addition of mirror-image $A \beta 42$ to the natural L-enantiomer. Angew. Chem. Int. Ed2017, 56, 11506-11510.

30. Dutta S; Rodriguez Foley A; Kuhn A; Abrams B; Lee H-W; Raskatov JA, New insights into differential aggregation of enantiomerically pure and racemic A $\beta 40$ systems. Peptide Sci. 2019, 111, e24139. 
31. Raskatov JA, Chiral inactivation: An old phenomenon with a new twist. Chem. Eur. J2017, 23, 16920-16923. [PubMed: 28948661]

32. Kodali R; Williams AD; Chemuru S; Wetzel R, A $\beta(1-40)$ forms five distinct amyloid structures whose $\beta$-sheet contents and fibril stabilities are correlated. J. Mol. Biol2010, 401, 503-517. [PubMed: 20600131]

33. Qiang W; Kelley K; Tycko R, Polymorph-specific kinetics and thermodynamics of $\beta$-amyloid fibril growth. J. Am. Chem. Soc2013, 135, 6860-6871. [PubMed: 23627695]

34. Rasmussen J; Mahler J; Beschorner N; Kaeser SA; Hasler LM; Baumann F; Nystrom S; Portelius E; Blennow K; Lashley T; Fox NC; Sepulveda-Falla D; Glatzel M; Oblak AL; Ghetti B; Nilsson KPR; Hammarstrom P; Staufenbiel M; Walker LC; Jucker M, Amyloid polymorphisms constitute distinct clouds of conformational variants in different etiological subtypes of Alzheimer's disease. Proc. Natl. Acad. Sci. USA2017, 114, 13018-13023. [PubMed: 29158413]

35. Qiang W; Yau WM; Tycko R, Structural evolution of Iowa mutant $\beta$-amyloid fibrils from polymorphic to homogeneous states under repeated seeded growth. J. Am. Chem. Soc2011, 133, 4018-4029. [PubMed: 21355554]

36. Astbury WT; Beighton E; Parker KD, The cross- $\beta$ configuration in supercontracted proteins. Biochim. Biophys. Acta1959, 35, 17-25. [PubMed: 13794874]

37. Eanes ED; Glenner GG, X-ray diffraction studies on amyloid filaments. J. Histochem. Cytochem1968, 16, 673-677. [PubMed: 5723775]

38. Benzinger TLS; Gregory DM; Burkoth TS; Miller-Auer H; Lynn DG; Botto RE; Meredith SC, Propagating structure of Alzheimer's $\beta$-amyloid(10-35) is parallel $\beta$-sheet with residues in exact register. Proc. Natl. Acad. Sci. USA1998, 95, 13407-13412. [PubMed: 9811813]

39. Antzutkin ON; Leapman RD; Balbach JJ; Tycko R, Supramolecular structural constraints on Alzheimer's $\beta$-amyloid fibrils from electron microscopy and solid-state nuclear magnetic resonance. Biochemistry2002, 41, 15436-15450. [PubMed: 12484785]

40. Goldsbury CS; Wirtz S; Muller SA; Sunderji S; Wicki P; Aebi U; Frey P, Studies on the in vitro assembly of $A \beta(1-40)$ : Implications for the search for $A \beta$ fibril formation inhibitors. J. Struct. Biol2000, 130, 217-231. [PubMed: 10940227]

41. Chen B; Thurber KR; Shewmaker F; Wickner RB; Tycko R, Measurement of amyloid fibril massper-length by tilted-beam transmission electron microscopy. Proc. Natl. Acad. Sci. USA2009, 106, 14339-14344. [PubMed: 19706519]

42. Zhang R; Hu XY; Khant H; Ludtke SJ; Chiu W; Schmid MF; Frieden C; Lee JM, Interprotofilament interactions between Alzheimer's $A \beta(1-42)$ peptides in amyloid fibrils revealed by cryoEM. Proc. Natl. Acad. Sci. USA2009, 106, 4653-4658. [PubMed: 19264960]

43. Lansbury PT; Costa PR; Griffiths JM; Simon EJ; Auger M; Halverson KJ; Kocisko DA; Hendsch ZS; Ashburn TT; Spencer RGS; Tidor B; Griffin RG, Structural model for the $\beta$-amyloid fibril based on interstrand alignment of an antiparallel-sheet comprising a C-terminal peptide. Nat. Struct. Biol1995, 2, 990-998. [PubMed: 7583673]

44. Balbach JJ; Ishii Y; Antzutkin ON; Leapman RD; Rizzo NW; Dyda F; Reed J; Tycko R, Amyloid fibril formation by $A \beta(16-22)$, a seven-residue fragment of the Alzheimer's $\beta$-amyloid peptide, and structural characterization by solid state NMR. Biochemistry2000, 39, 13748-13759. [PubMed: 11076514]

45. Petkova AT; Buntkowsky G; Dyda F; Leapman RD; Yau WM; Tycko R, Solid state NMR reveals a $\mathrm{pH}$-dependent antiparallel $\beta$-sheet registry in fibrils formed by a $\beta$-amyloid peptide. J. Mol. Biol2004, 335, 247-260. [PubMed: 14659754]

46. Raskatov JA, Conformational selection as the driving force of amyloid $\beta$ chiral inactivation. ChemBioChem2020, 21, 2945-2949. [PubMed: 32424959]

47. Raskatov JA, A DFT study of structure and stability of pleated and rippled cross- $\beta$ sheets with hydrophobic sidechains. Biopolymers2020, e23391. [PubMed: 32737991]

48. Raskatov JA; Schneider JP; Nilsson BL, Defining the landscape of the Pauling-Corey rippled sheet: An orphaned motif finding new homes. Acc. Chem. Res2021, 54, 2488-2501. [PubMed: 33901396]

49. Nagy-Smith K; Beltramo PJ; Moore E; Tycko R; Furst EM; Schneider JP, Molecular, local, and network-level basis for the enhanced stiffness of hydrogel networks formed from coassembled 
racemic peptides: Predictions from Pauling and Corey. ACS Cent. Sci2017, 3, 586-597. [PubMed: 28691070]

50. Bieschke J; Herbst M; Wiglenda T; Friedrich RP; Boeddrich A; Schiele F; Kleckers D; Lopez del Amo JM; Grüning BA; Wang Q; Schmidt MR; Lurz R; Anwyl R; Schnoegl S; Fändrich M; Frank RF; Reif B; Günther S; Walsh DM; Wanker EE, Small-molecule conversion of toxic oligomers to nontoxic $\beta$-sheet-rich amyloid fibrils. Nat. Chem. Biol2012, 8, 93-101.

51. Sonzini S; Stanyon HF; Scherman OA, Decreasing amyloid toxicity through an increased rate of aggregation. Phys. Chem. Chem. Phys2017, 19, 1458-1465. [PubMed: 27982149]

52. Funke SA; Bartnik D; Gluck JM; Piorkowska K; Wiesehan K; Weber U; Gulyas B; Halldin C; Pfeifer A; Spenger C; Muhs A; Willbold D, Development of a small D-enantiomeric Alzheimer's amyloid- $\beta$ binding peptide ligand for future in vivo imaging applications. PLoS One2012, 7, e41457. [PubMed: 22848501]

53. Sievers SA; Karanicolas J; Chang HW; Zhao A; Jiang L; Zirafi O; Stevens JT; Munch J; Baker D; Eisenberg D, Structure-based design of non-natural amino-acid inhibitors of amyloid fibril formation. Nature2011, 475, 96-100. [PubMed: 21677644]

54. Wiesehan K; Stohr J; Nagel-Steger L; van Groen T; Riesner D; Willbold D, Inhibition of cytotoxicity and amyloid fibril formation by a D-amino acid peptide that specifically binds to Alzheimer's disease amyloid peptide. Protein Eng. Des. Sel2008, 21, 241-246. [PubMed: 18252750]

55. Kumar J; Sim V, D-amino acid-based peptide inhibitors as early or preventative therapy in Alzheimer disease. Prion2014, 8, 118-123.

56. Pauling L; Corey RB, Two rippled-sheet configurations of polypeptides chains, and a note about the pleated sheets. Proc. Natl. Acad. Sci. USA1953, 39, 253-256. [PubMed: 16589257]

57. Pauling L; Corey RB, Configurations of polypeptide chains with favored orientations around single bonds: Two new pleated sheets. Proc. Natl. Acad. Sci. USA1951, 37, 729-740. [PubMed: 16578412]

58. Swanekamp RJ; DiMaio JTM; Bowerman CJ; Nilsson BL, Coassembly of enantiomeric amphipathic peptides into amyloid-inspired rippled $\beta$-sheet fibrils. J. Am. Chem. Soc2012, 134, 5556-5559. [PubMed: 22420540]

59. Urban JM; Ho J; Piester G; Fu R; Nilsson BL, Rippled $\beta$-sheet formation by an amyloid$\beta$ fragment indicates expanded scope of sequence space for enantiomeric $\beta$-sheet peptide coassembly. Molecules2019, 24, 1983.

60. Wadai H; Yamaguchi K; Takahashi S; Kanno T; Kawai T; Naiki H; Goto Y, Stereospecific amyloid-like fibril formation by a peptide fragment of $\beta(2)$-microglobulin. Biochemistry2005, 44, 157-164. [PubMed: 15628856]

61. Torbeev V; Grogg M; Ruiz J; Boehringer R; Schirer A; Hellwig P; Jeschke G; Hilvert D, Chiral recognition in amyloid fiber growth. J. Pept. Sci2016, 22, 290-304. [PubMed: 26929241]

62. Foley AR; Raskatov JA, Assessing reproducibility in amyloid $\beta$ research: Impact of A $\beta$ sources on experimental outcomes. ChemBioChem2020, 21, 2425-2430. [PubMed: 32249510]

63. Lucast LJ; Batey RT; Doudna JA, Large-scale purification of a stable form of recombinant tobacco etch virus protease. Biotechniques2001, 30, 544-554. [PubMed: 11252791]

64. Tycko R, Symmetry-based constant-time homonuclear dipolar recoupling in solid state NMR. J. Chem. Phys2007, 126, 064506. [PubMed: 17313228]

65. Petkova AT; Tycko R, Sensitivity enhancement in structural measurements by solid state NMR through pulsed spin locking. J. Magn. Reson2002, 155, 293-299. [PubMed: 12036340]

66. Anderson RC; Gullion T; Joers JM; Shapiro M; Villhauer EB; Weber HP, Conformation of 1-13C,15N acetyl-L-carnitine: Rotational-echo, double-resonance nuclear magnetic resonance spectroscopy. J. Am. Chem. Soc1995, 117, 10546-10550.

67. Bennett AE; Rienstra CM; Auger M; Lakshmi KV; Griffin RG, Heteronuclear decoupling in rotating solids. J. Chem. Phys1995, 103, 6951-6958.

68. Gullion T; Baker DB; Conradi MS, New, compensated Carr-Purcell sequences. J. Magn. Reson1990, 89, 479-484.

69. Tycko R; Pines A; Guckenheimer J, Fixed-point theory of iterative excitation schemes in NMR. J. Chem. Phys 1985, 83, 2775-2802. 
70. Delaglio F; Grzesiek S; Vuister GW; Zhu G; Pfeifer J; Bax A, NMRpipe: A multidimensional spectral processing system based on Unix pipes. J. Biomol. NMR1995, 6, 277-293. [PubMed: 8520220]

71. Ditchfield R; Hehre WJ; Pople JA, Self-consistent molecular orbital methods. 9. Extended Gaussian-type basis for molecular orbital studies of organic molecules. J. Chem. Phys1971, 54, 724-728.

72. Hehre WJ; Ditchfield R; Pople JA, Self-consistent molecular orbital methods. 12. Further extensions of Gaussian-type basis sets for use in molecular orbital studies of organic molecules. J. Chem. Phys 1972, 56, 2257-2261.

73. Zhao Y; Truhlar DG, The M06 suite of density functionals for main group thermochemistry, thermochemical kinetics, noncovalent interactions, excited states, and transition elements: Two new functionals and systematic testing of four M06-class functionals and twelve other functionals. Theor. Chem. Acc2008, 120, 215-241.

74. Frisch MJ; Trucks GW; Schlegel HB; Scuseria GE; Robb MA; Cheeseman JR; Scalmani G; Barone V; Mennucci B; Petersson GA; Nakatsuji H; Caricato M; Li X; Hratchian HP; Izmaylov AF; Bloino J; Zheng G; Sonnenberg JL; Hada M; Ehara M; Toyota K; Fukuda R; Hasegawa J; Ishida M; Nakajima T; Honda Y; Kitao O; Nakai H; Vreven T Jr; Peralta JE; Ogliaro F; Bearpark M; Heyd JJ; Brothers E; Kudin KN; Staroverov VN; Kobayashi R; Normand J; Raghavachari K; Rendell A; Burant JC; Iyengar SS; Tomasi J; Cossi M; Rega N; Millam JM; Klene M; Knox JE; Cross JB; Bakken V; Adamo C; Jaramillo J; Gomperts R; Stratmann RE; Yazyev O; Austin AJ; Cammi R; Pomelli C; Ochterski JW; Martin RL; Morokuma K; Zakrzewski VG; Voth GA; Salvador P; Dannenberg JJ; Dapprich S; Daniels AD; Farkas; Foresman JB; Ortiz JV; Cioslowski J; Fox DJ, Gaussian 09 revision A.02. Gaussian Inc. Wallingford CT2009: 2009.

75. Shen Y; Bax A, Protein backbone and sidechain torsion angles predicted from NMR chemical shifts using artificial neural networks. J. Biomol. NMR2013, 56, 227-241. [PubMed: 23728592]

76. Wishart DS; Bigam CG; Holm A; Hodges RS; Sykes BD, 1H, 13C and 15N random coil NMR chemical-shifts of the common amino acids. 1. Investigations of nearest-neighbor effects. J. Biomol. NMR1995, 5, 67-81. [PubMed: 7881273]

77. Fitzpatrick AWP; Falcon B; He S; Murzin AG; Murshudov G; Garringer HJ; Crowther RA; Ghetti B; Goedert M; Scheres SHW, Cryo-EM structures of tau filaments from Alzheimer's disease. Nature2017, 547, 185-190. [PubMed: 28678775]

78. Nagy KJ; Giano MC; Jin A; Pochan DJ; Schneider JP, Enhanced mechanical rigidity of hydrogels formed from enantiomeric peptide assemblies. J. Am. Chem. Soc2011, 133, 14975-14977. [PubMed: 21863803]

79. Grelich-Mucha M; Garcia AM; Torbeev V; Ozga K; Berlicki L; Olesiak-Banska J, Autofluorescence of amyloids determined by enantiomeric composition of peptides. J. Phys. Chem. B2021, 125, 5502-5510. [PubMed: 34008978]

80. Fitzpatrick AWP; Debelouchina GT; Bayro MJ; Clare DK; Caporini MA; Bajaj VS; Jaroniec CP; Wang LC; Ladizhansky V; Muller SA; MacPhee CE; Waudby CA; Mott HR; De Simone A; Knowles TPJ; Saibil HR; Vendruscolo M; Orlova EV; Griffin RG; Dobson CM, Atomic structure and hierarchical assembly of a cross- $\beta$ amyloid fibril. Proc. Natl. Acad. Sci. USA2013, 110, 54685473. [PubMed: 23513222]

81. Perutz MF; Johnson T; Suzuki M; Finch JT, Glutamine repeats as polar zippers: Their possible role in inherited neurodegenerative diseases. Proc. Natl. Acad. Sci. USA1994, 91, 5355-5358. [PubMed: 8202492]

82. Gazit E, A possible role for $\pi$-stacking in the self-assembly of amyloid fibrils. FASEB J. 2002, 16, 77-83. [PubMed: 11772939] 

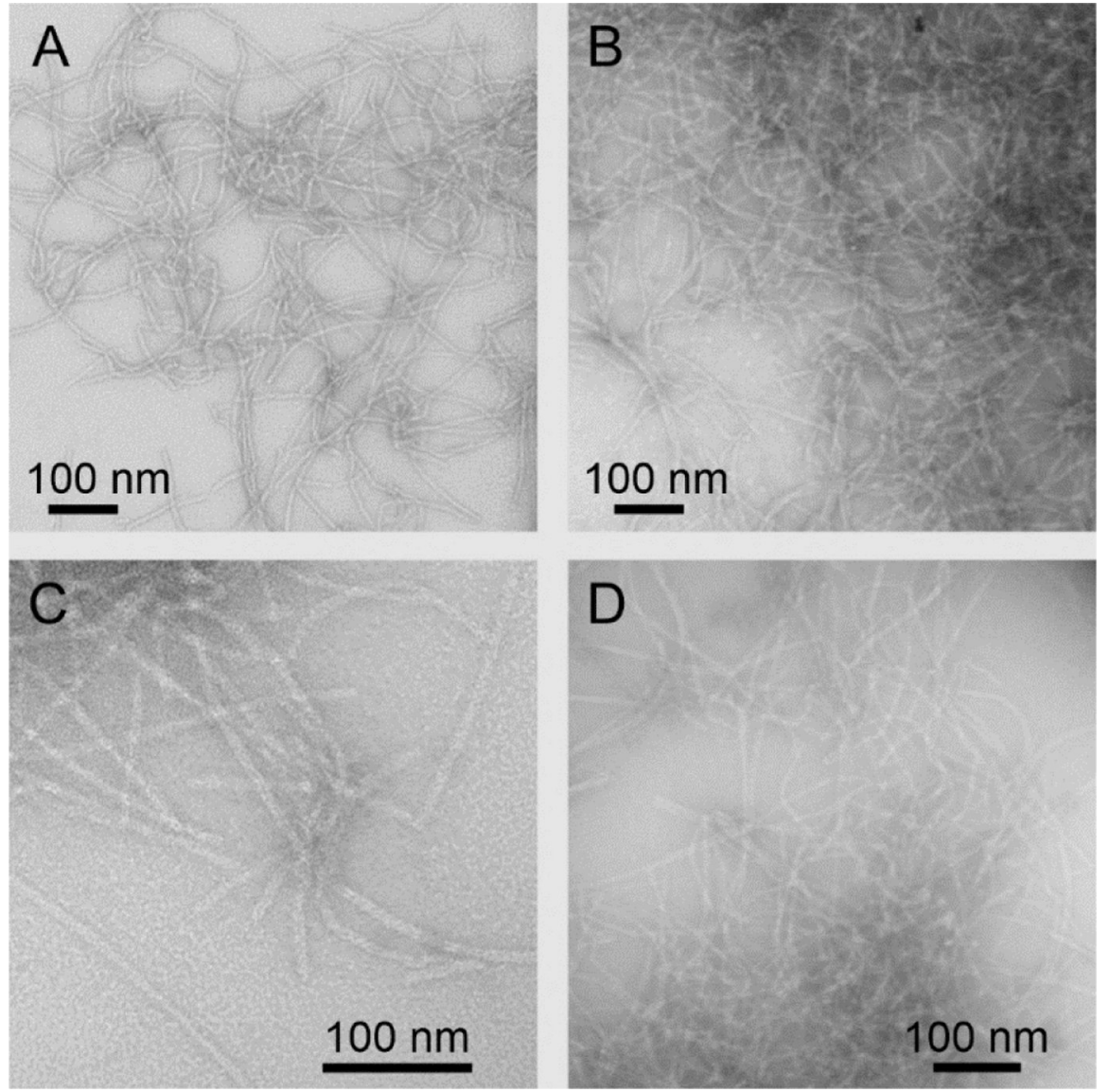

Figure 1:

Negative-stain TEM images of D,L-A $\beta 40$ fibrils. (A,B) $3 \mathrm{~N}_{\mathrm{L}}, 3 \mathrm{C}_{\mathrm{L}}-\mathrm{D}, \mathrm{L}-\mathrm{A} \beta 40$ fibrils after $16 \mathrm{~h}$ and $100 \mathrm{~h}$ of incubation, respectively. (C,D) $\mathrm{U}_{\mathrm{L}}-\mathrm{D}, \mathrm{L}-\mathrm{A} \beta 40$ fibrils after $120 \mathrm{~h}$ of incubation. In both cases, fibrils were grown under quiescent conditions in PBS at $24^{\circ} \mathrm{C}$ and $\mathrm{pH} 7.4$ with a total peptide concentration of $40 \mu \mathrm{M}$. Peptides were disaggregated in $20 \mathrm{mM}$ $\mathrm{NaOH}$ prior to mixing and dilution into PBS. 

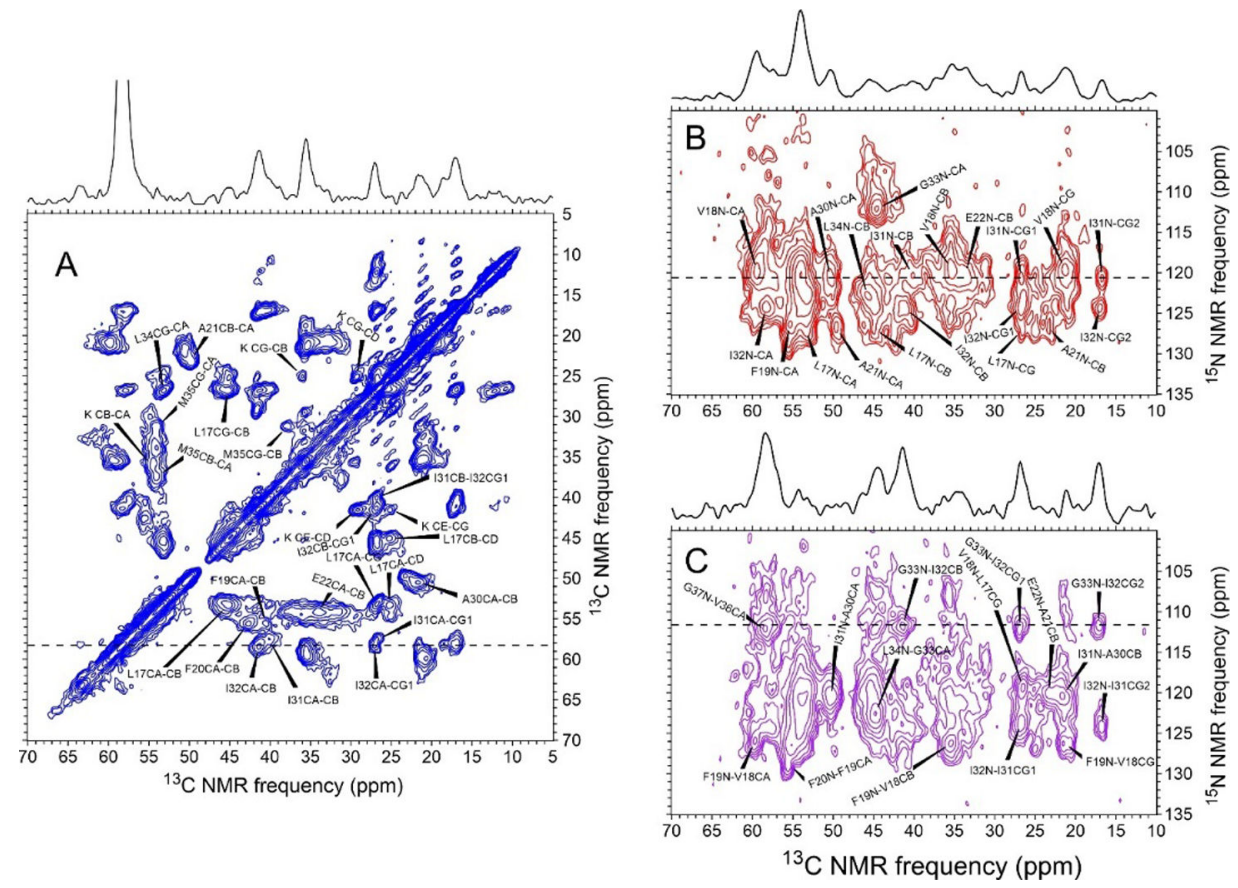

Figure 2:

${ }_{2 \mathrm{D}}{ }^{13} \mathrm{C}-{ }^{13} \mathrm{C}$ (A), NCACX (B) and NCOCX (C) solid state NMR spectra of $\mathrm{U}_{\mathrm{L}}-\mathrm{D}, \mathrm{L}-\mathrm{A} \beta 40$ fibrils. 1D slices above each 2D spectrum are taken at positions indicated by dashed lines. Contour levels increase by successive factors of 1.4. Crosspeak assignments were obtained from 3D solid state NMR spectra (see Fig. 3). 

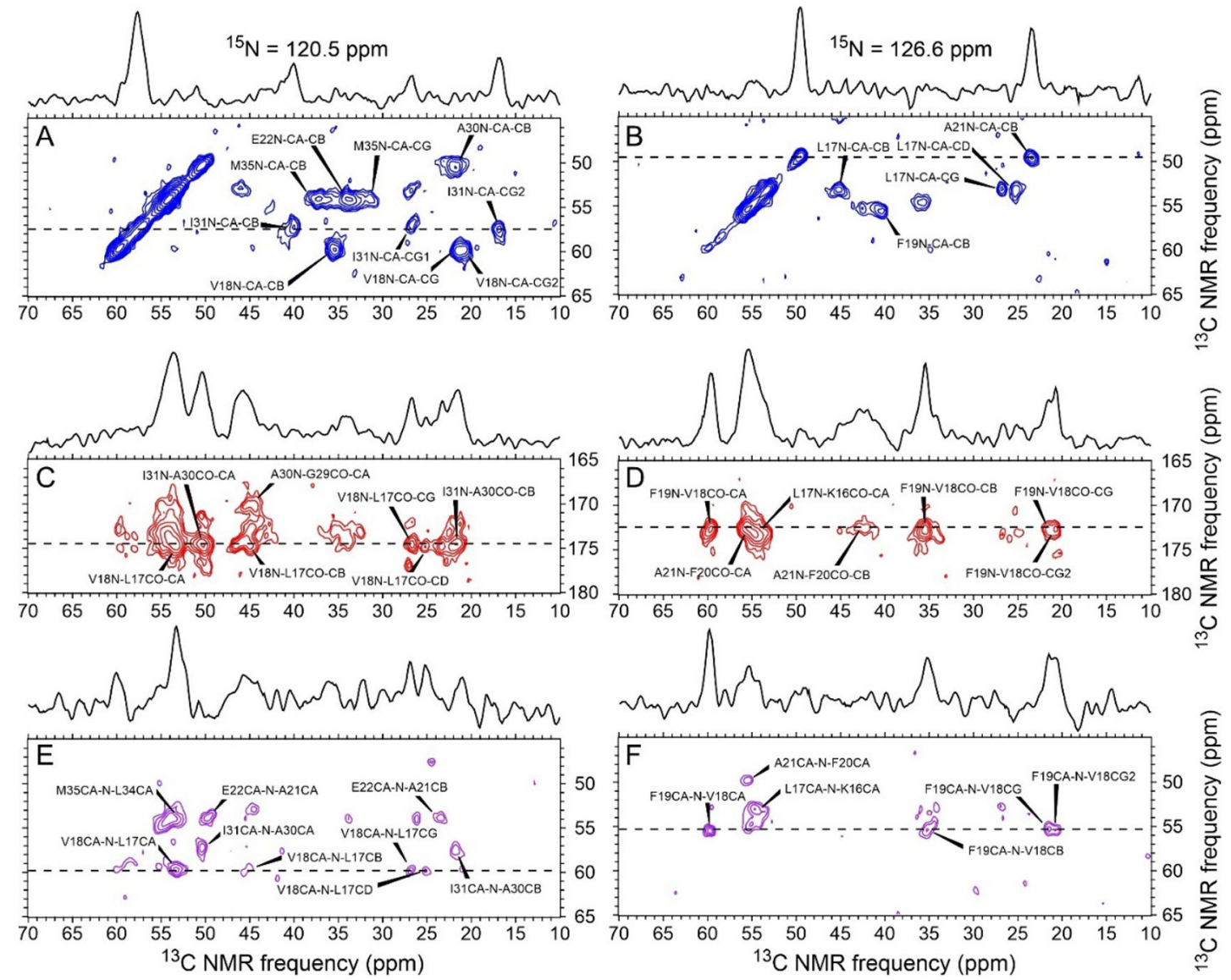

Figure 3:

Examples of 2D planes from 3D solid state NMR spectra of $U_{L}-D, L-A \beta 40$ fibrils. ${ }^{13} \mathrm{C}-{ }^{13} \mathrm{C}$ planes from 3D NCACX (A,B), NCOCX (C,D), and CANCX (E,F) spectra are shown at ${ }^{15} \mathrm{~N}$ chemical shifts of $120.5 \mathrm{ppm}(\mathrm{A}, \mathrm{C}, \mathrm{E})$ and $126.6 \mathrm{ppm}(\mathrm{B}, \mathrm{D}, \mathrm{F})$. 1D slices in each panel are taken at positions indicated by dashed lines. Contour levels increase by successive factors of 1.4. Assignments are shown for crosspeaks with ${ }^{15} \mathrm{~N}$ chemicals shifts within $\pm 1.5 \mathrm{ppm}$ of the indicated values. 


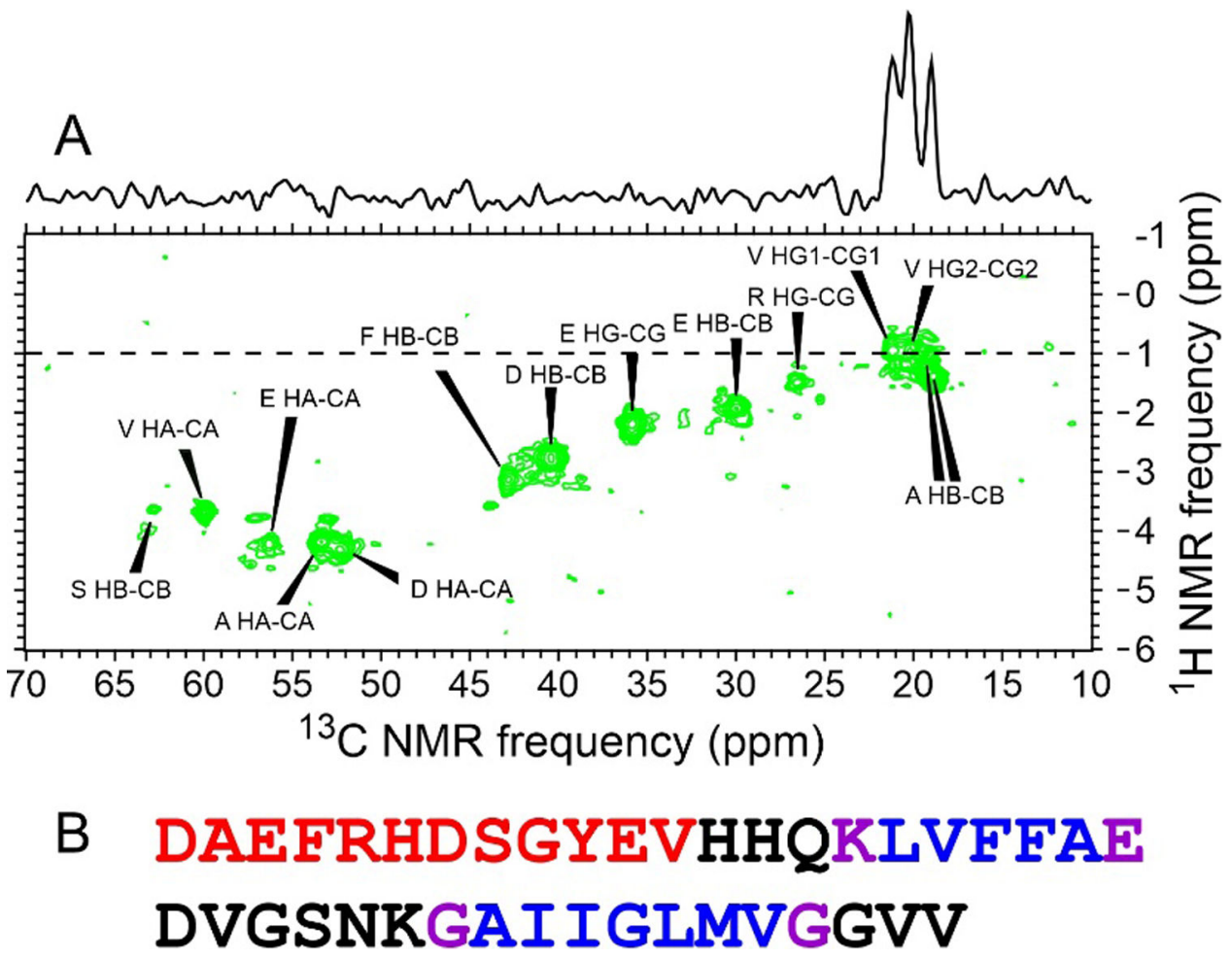

Figure 4:

(A) $2 \mathrm{D}{ }^{1} \mathrm{H}_{-}{ }^{13} \mathrm{C}$ INEPT spectrum of $\mathrm{U}_{\mathrm{L}}-\mathrm{D}, \mathrm{L}-\mathrm{A} \beta 40$ fibrils, showing signals from residues that remain dynamically disordered. Residue-type assignments are based on standard randomcoil chemical shifts. The $1 \mathrm{D}$ slice above the $2 \mathrm{D}$ spectrum is taken at the position indicated by the dashed line. Contour levels increase by successive factors of 1.4. (B) A $\beta 40$ sequence, with $\beta$-strand segments in blue, additional residues with assigned solid state NMR signals in purple, and the dynamically disordered $\mathrm{N}$-terminal segment in red. 

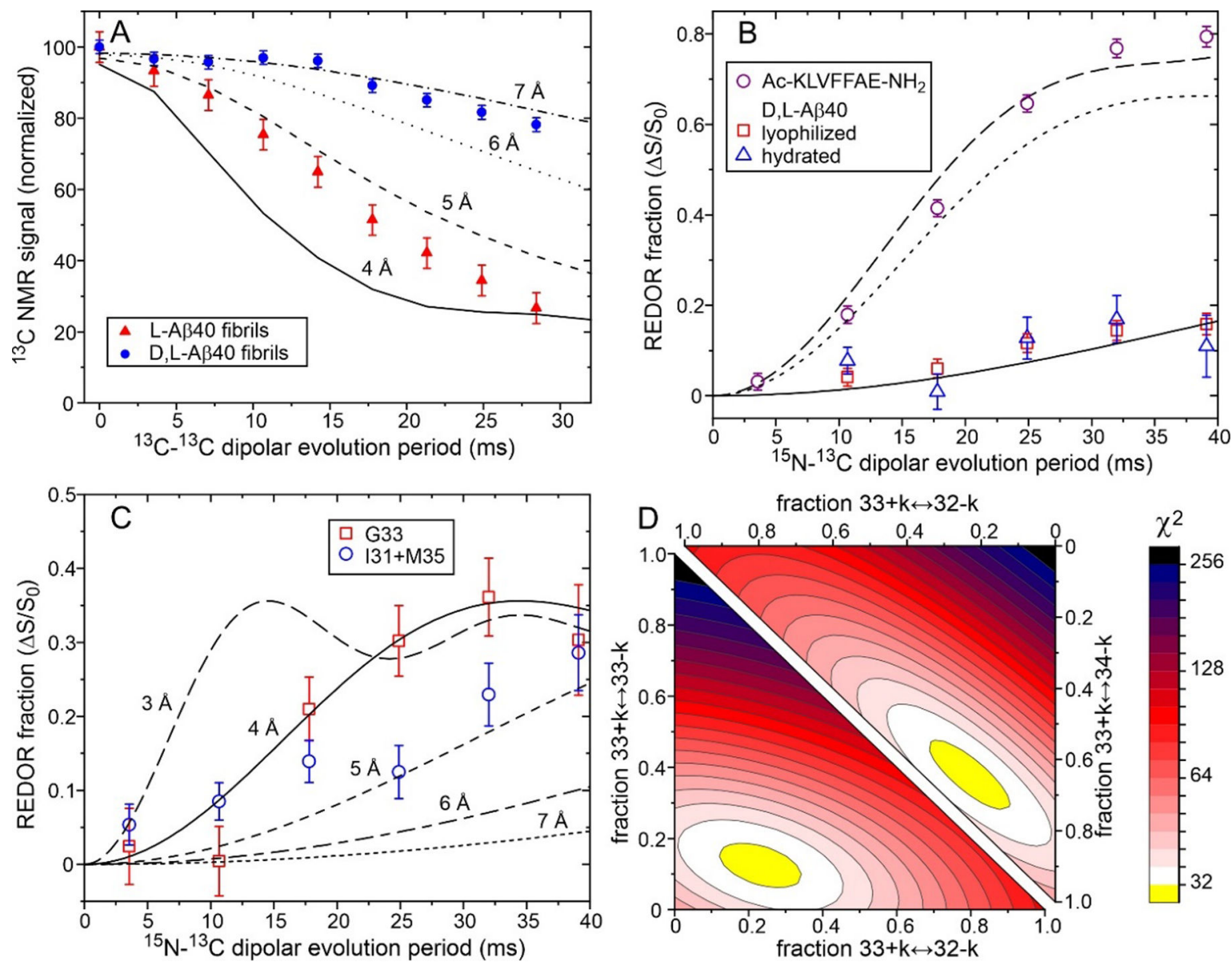

Figure 5:

(A) Measurements of ${ }^{13} \mathrm{C}_{-}{ }^{13} \mathrm{C}$ dipole-dipole couplings in $3 \mathrm{~N}_{\mathrm{L}}, 3 \mathrm{C}_{\mathrm{L}}-\mathrm{D}, \mathrm{L}-\mathrm{A} \beta 40$ fibrils (blue circles) and L-A $\beta 40$ fibrils with ${ }^{13} \mathrm{C}$ labels at carbonyl sites of I31, G33, and M35 (red triangles), using the PITHIRDS-CT solid state NMR technique. Signal amplitudes are normalized to 100 at an evolution time of zero. Error bars are uncertainties due to the root-mean-squared noise in the experimental spectra. Solid, dashed, dotted, and dash-dotted lines are numerical simulations of PITHIRDS-CT data for linear chains of ${ }^{13} \mathrm{C}$ nuclei with the indicated internuclear distances. (B) Measurements of ${ }^{15} \mathrm{~N}-{ }^{13} \mathrm{C}$ dipole-dipole couplings in $2 \mathrm{C}_{\mathrm{L}}, 2 \mathrm{~N}_{\mathrm{D}}$-D,L-A $\beta 40$ (blue triangles and red squares for fully hydrated and lyophilized fibrils, respectively), using the ${ }^{13} \mathrm{C}$-detected REDOR solid state NMR technique. REDOR data for Ac-KLVFFAE- $\mathrm{NH}_{2}$ fibrils with amide ${ }^{15} \mathrm{~N}$ and carbonyl ${ }^{13} \mathrm{C}$ labels at $\mathrm{V} 3$ and $\mathrm{F} 5$ are also shown (purple circles). Solid and dotted lines are REDOR simulations for hypothetical antiparallel and in-register parallel rippled sheet structures, respectively, for D,L-A 340 fibrils. The dashed line is a REDOR simulation for Ac-KLVFFAE- $\mathrm{NH}_{2}$ fibrils with their known intermolecular V3-F5 hydrogen bonds. (C) REDOR data for $3 \mathrm{~N}_{\mathrm{L}}, 3 \mathrm{C}_{\mathrm{L}}, 2 \mathrm{~N}_{\mathrm{D}}$-D, LA $\beta 40$ fibrils. Results for the carbonyl ${ }^{13} \mathrm{C}$ signals of $\mathrm{G} 33$ (red squares) and I31/M35 (unresolved, blue circles) are plotted separately. Lines are two-spin REDOR simulations for the indicated ${ }^{15} \mathrm{~N}-{ }^{13} \mathrm{C}$ distances, scaled by a factor of 0.38 . (D) Contour plot of the $\chi^{2}$ deviation between experimental REDOR data for D,L-A $\beta 40$ fibrils and simulations in which 
the relative populations of antiparallel rippled sheets with three possible hydrogen bond registries were varied. 

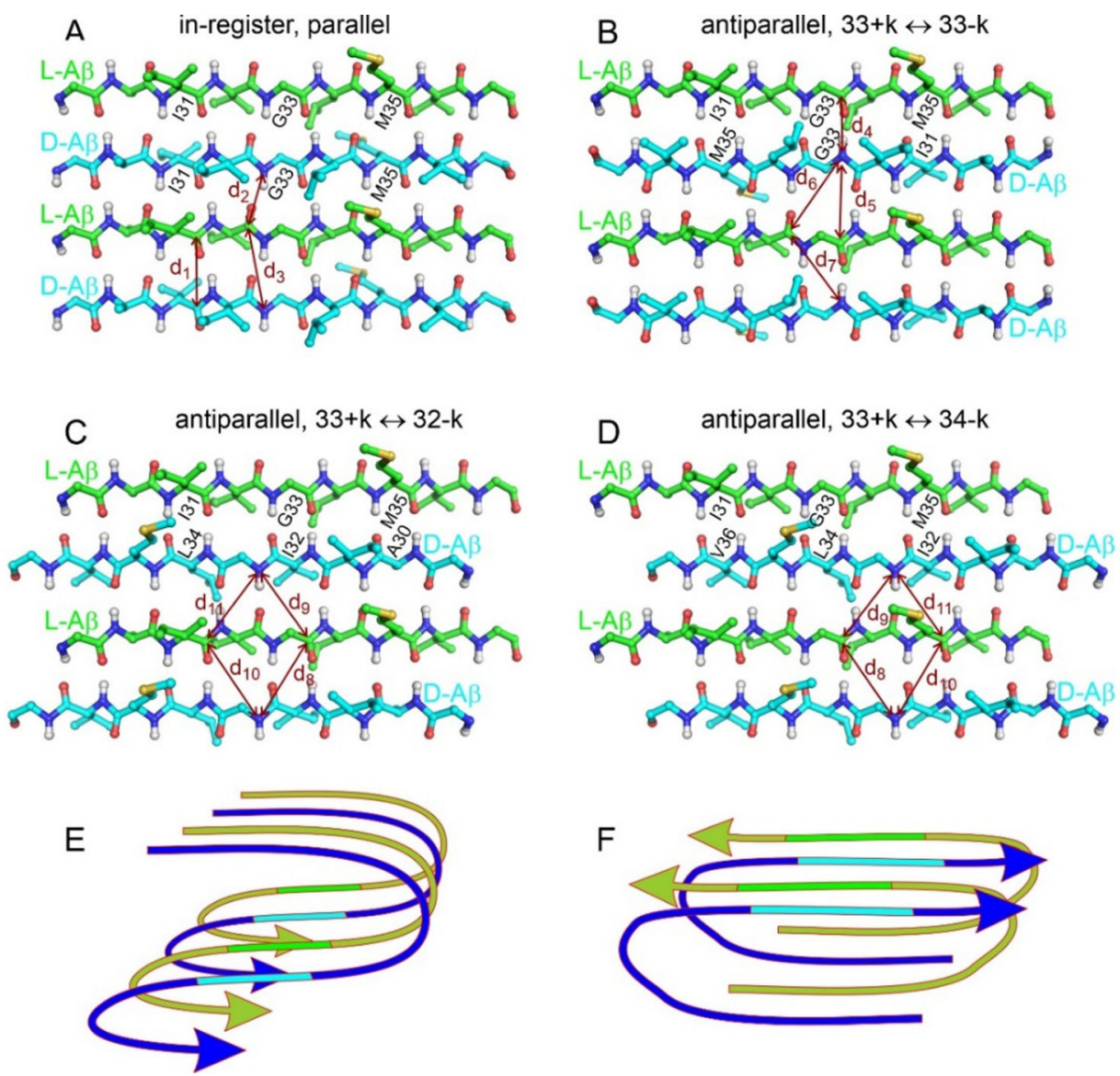

Figure 6:

Models for $\beta$-sheets formed by residues 29-37 of A $\beta 40$ (sequence GAIIGLMVG), with alternation between $\mathrm{D}$ and $\mathrm{L}$ molecules along the intermolecular hydrogen bonding direction. (A) In-register, parallel $\beta$-sheet model. Carbon-carbon distance $\mathrm{d}_{1}$ is $4.8 \AA$. Nitrogen-carbon distances $\mathrm{d}_{2}$ and $\mathrm{d}_{3}$ are $4.1 \AA$ and $5.8 \AA$, respectively. (B) Antiparallel $\beta$-sheet model with $33+\mathrm{k} \leftrightarrow 33$-k registry. Nitrogen-carbon distances $\mathrm{d}_{4}$ and $\mathrm{d}_{5}$ from the carbonyl carbon of G33 in L-A $\beta 40$ are $4.1 \AA$ and $5.9 \AA$. Distances $\mathrm{d}_{6}$ and $\mathrm{d}_{7}$ from the carbonyl carbon of I32 are $6.0 \AA$ and $6.4 \AA$. (C,D) Antiparallel $\beta$-sheet models with $33+\mathrm{k}$ $\leftrightarrow 32-\mathrm{k}$ and $33+\mathrm{k} \leftrightarrow 34-\mathrm{k}$ registry. Distances $\mathrm{d}_{8}$ and $\mathrm{d}_{10}$ are $6.4 \AA$, and $\mathrm{d}_{9}$ and $\mathrm{d}_{11}$ are 6.0 $\AA$. With $33+\mathrm{k} \leftrightarrow 32-\mathrm{k}$ registry, $\mathrm{d}_{10}$ and $\mathrm{d}_{11}$ are distances from the carbonyl carbon of $\mathrm{I} 31$. With $33+\mathrm{k} \leftrightarrow 34-\mathrm{k}$ registry, $\mathrm{d}_{10}$ and $\mathrm{d}_{11}$ are distances from the carbonyl carbon of M35. (E) Cartoon representation of an in-register, parallel cross- $\beta$ motif comprised of alternating D and $\mathrm{L}$ peptides with $\mathrm{S}$-shaped conformations. (F) Cartoon representation of an antiparallel cross- $\beta$ motif comprised of alternating $\mathrm{D}$ and $\mathrm{L}$ peptides with $\mathrm{U}$-shaped conformations. 

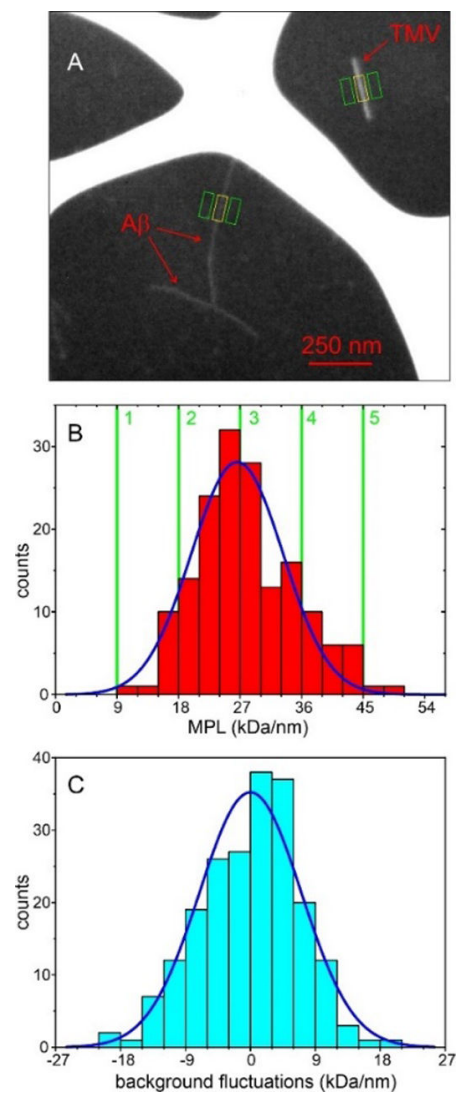

Figure 7:

(A) Example of a dark-field TEM image of unstained D,L-A $\beta 40$ fibrils. MPL values were determined from integrated image intensities within $100 \mathrm{~nm} \times 40 \mathrm{~nm}$ areas (yellow rectangles) after subtraction of integrated background intensities (green rectangles). Intensities were calibrated by similar measurements on co-adsorbed tobacco mosaic virus rods (TMV). (B) Histogram of MPL values, obtained from 163 fibril segments and $43 \mathrm{TMV}$ segments in measurements in 27 dark-field images. Blue line is a best-fit Gaussian curve, centered at $26.6 \pm 0.5 \mathrm{kDa} / \mathrm{nm}$ with $15.8 \pm 1.2 \mathrm{kDa} / \mathrm{nm}$ full-width-at-half-maximum. Vertical green lines indicate ideal MPL values for hypothetical structures with $1-5$ cross- $\beta$ subunits. (C) Histogram of the expected errors in MPL values due to background noise fluctuations in individual dark-field images. Blue line is a best-fit Gaussian curve, centered at $0.0 \mathrm{kDa} / \mathrm{nm}$ with $16.6 \pm 1.0 \mathrm{kDa} / \mathrm{nm}$ full-width-at-half-maximum. 


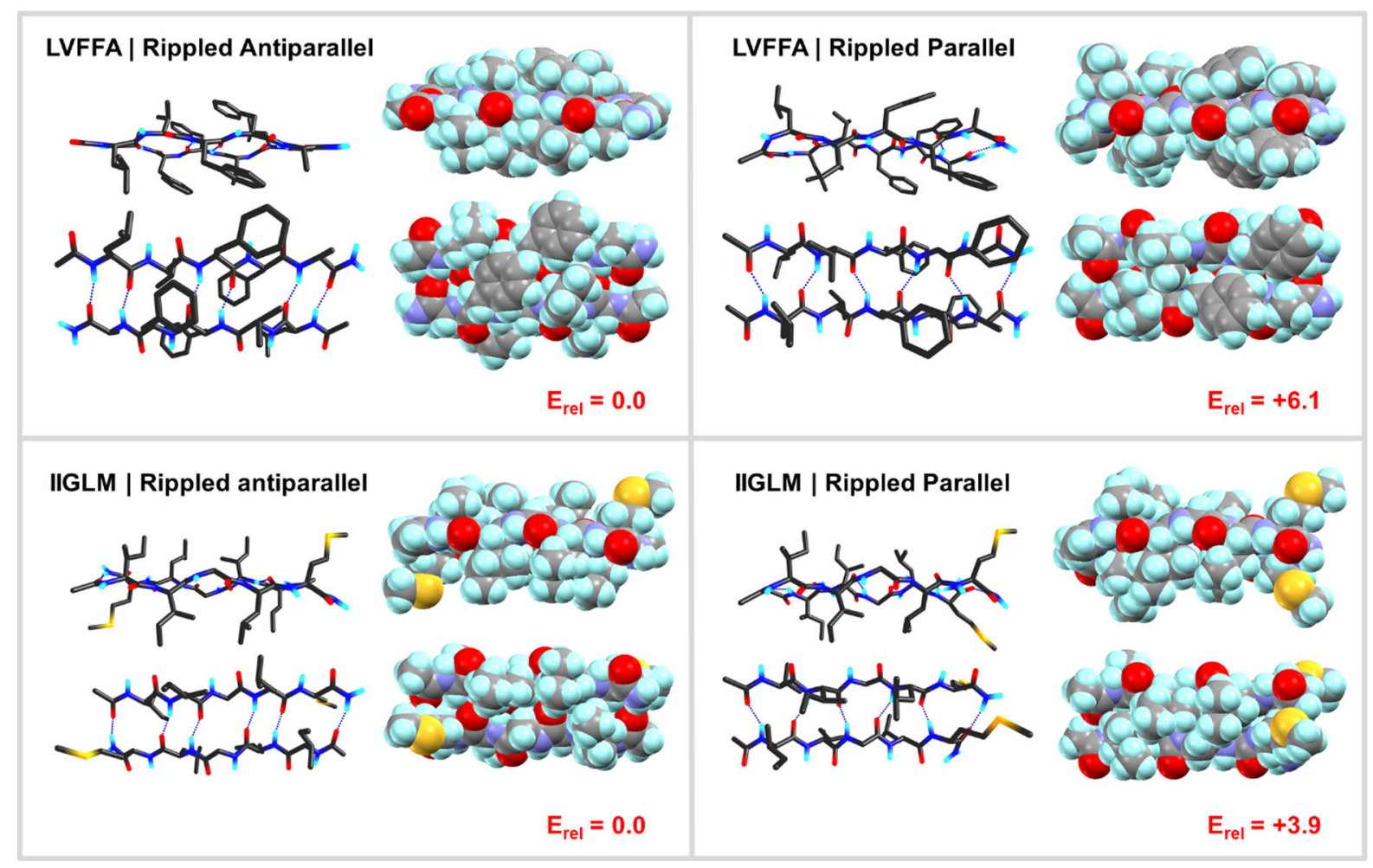

Figure 8:

DFT-optimized partial structures corresponding to the rippled LVFFA:lvffa (top) and IIGLM:iiglm (bottom) in either antiparallel (left) or parallel (right) orientation. In each case, two views are shown, rotated by $90^{\circ}$ about a horizontal line. Structures are shown in both stick and space-filling representations. Relative energies $\mathrm{E}_{\mathrm{rel}}$ are given in $\mathrm{kcal} / \mathrm{mol}$. 
Table 1:

Isotopic labeling patterns in D,L-A 440 fibril samples

\begin{tabular}{|l|l|l|l|}
\hline fibril sample & labeling of L-A $\beta 40$ & labeling of D-A $\beta 40$ & solid state NMR measurements \\
\hline $\mathrm{U}_{\mathrm{L}}-\mathrm{D}, \mathrm{L}-\mathrm{A} \beta 40$ & uniformly ${ }^{15} \mathrm{~N}$ and ${ }^{13} \mathrm{C}$ & none & $\begin{array}{l}2 \mathrm{D}{ }^{13} \mathrm{C}-{ }^{13} \mathrm{C}, \text { 2D NCACX, 2D NCOCX, } \\
\text { NCOCX, 3D CONCA }\end{array}$ \\
\hline $3 \mathrm{~N}_{\mathrm{L}}, 3 \mathrm{C}_{\mathrm{L}}$-D,L-A $\mathrm{C} 40$ & $\begin{array}{l}{ }^{15} \mathrm{~N} \text { at L17, F19, A21; carbonyl }{ }^{13} \mathrm{C} \text { at I31, } \\
\mathrm{G} 33, \mathrm{M} 35\end{array}$ & none & ${ }^{13} \mathrm{C}$ PITHIRDS-CT \\
\hline $2 \mathrm{C}_{\mathrm{L}}, 2 \mathrm{~N}_{\mathrm{D}}-\mathrm{D}, \mathrm{L}-\mathrm{A} \beta 40$ & carbonyl ${ }^{13} \mathrm{C}$ at I32, V36 & ${ }^{15} \mathrm{~N}$ at G33, G37 & ${ }^{15} \mathrm{~N}-{ }^{13} \mathrm{C}$ REDOR \\
\hline $3 \mathrm{~N}_{\mathrm{L}}, 3 \mathrm{C}_{\mathrm{L}}, 2 \mathrm{~N}_{\mathrm{D}}-\mathrm{D}, \mathrm{L}-\mathrm{A} \beta 40$ & $\begin{array}{l}{ }^{15} \mathrm{~N} \text { at L17, F19, A21; carbonyl }{ }^{13} \mathrm{C} \text { at I31, } \\
\mathrm{G} 33, \mathrm{M} 35\end{array}$ & ${ }^{15} \mathrm{~N}$ at G33, G37 & ${ }^{15} \mathrm{~N}-{ }^{13} \mathrm{C}$ REDOR \\
\hline
\end{tabular}


Table 2:

${ }^{13} \mathrm{C}$ and ${ }^{15} \mathrm{~N}$ NMR chemical shifts for D,L-A $\beta 40$ fibrils, determined from 3D solid state NMR spectra. ${ }^{13} \mathrm{C}$ shifts are in parts per million relative to DSS. ${ }^{15} \mathrm{~N}$ shifts are in parts per million relative to liquid ammonia. Predicted backbone $\phi, \psi$ torsion angles from the TALOS-N program are also shown in degrees, along with uncertainties reported by TALOS-N. Only predictions classified by TALOS-N as "strong" are shown

\begin{tabular}{|l|l|l|l|l|l|l|l|l|l|l|}
\hline & CA & CB & CD & CG & CG1 & CG2 & CO & N & $\phi$ & $\Psi$ \\
\hline K16 & 54.6 & - & - & - & - & - & 173.2 & - & & \\
\hline L17 & 53.25 & 45.1 & 25.14 & 26.67 & - & - & 174.8 & 126.8 & $-110 \pm 14$ & $137 \pm 10$ \\
\hline V18 & 59.65 & 35.36 & - & - & 21.48 & 20.79 & 172.7 & 119.7 & $-127 \pm 13$ & $141 \pm 12$ \\
\hline F19 & 55.45 & 40.48 & - & - & - & - & 172.4 & 126.4 & $-106 \pm 10$ & $125 \pm 7$ \\
\hline F20 & 55.54 & 42.54 & - & - & - & - & 172.3 & 129.5 & $-117 \pm 11$ & $135 \pm 10$ \\
\hline A21 & 49.71 & 23.36 & - & - & - & - & - & 126.8 & $-129 \pm 14$ & $148 \pm 11$ \\
\hline E22 & 53.94 & 33.9 & 181.8 & 36.77 & - & - & - & 120 & & \\
\hline G29 & 44.86 & - & - & - & - & - & 170.1 & - & & \\
\hline A30 & 50.36 & 21.68 & - & - & - & - & 174.6 & 120.7 & $-129 \pm 14$ & $148 \pm 10$ \\
\hline I31 & 57.38 & 40.15 & - & - & 26.78 & 16.79 & 173.8 & 120.6 & $-117 \pm 14$ & $140 \pm 11$ \\
\hline I32 & 58.26 & 41.41 & - & - & 26.86 & 17.07 & 173.3 & 124.3 & $-129 \pm 10$ & $143 \pm 8$ \\
\hline G33 & 44.72 & - & - & - & - & - & 170.2 & 111.9 & $-159 \pm 25$ & $172 \pm 19$ \\
\hline L34 & 52.84 & 46.05 & - & 26.78 & - & - & - & 122.8 & $-127 \pm 13$ & $143 \pm 11$ \\
\hline M35 & 54.01 & 37.78 & - & 31.2 & - & - & 173.7 & 119.3 & $-129 \pm 9$ & $148 \pm 12$ \\
\hline V36 & 58.58 & 35.78 & - & 21.17 & - & - & 173.6 & 116.9 & $-132 \pm 9$ & $154 \pm 10$ \\
\hline G37 & 45.24 & - & - & - & - & - & - & 112.1 & & \\
\hline
\end{tabular}

